\begin{tabular}{|c|c|c|}
\hline 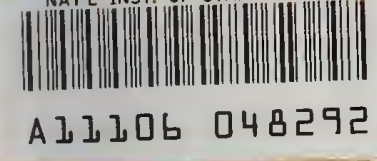 & eference & $\begin{array}{l}\text { ivBS } \\
\text { Publi- } \\
\text { cations }\end{array}$ \\
\hline
\end{tabular}

National Bureau

of Standards

\title{
An Overview of Artificial Intelligence and Robotics Volume II - Robotics
}

March 1982

NBSIR 82-2479

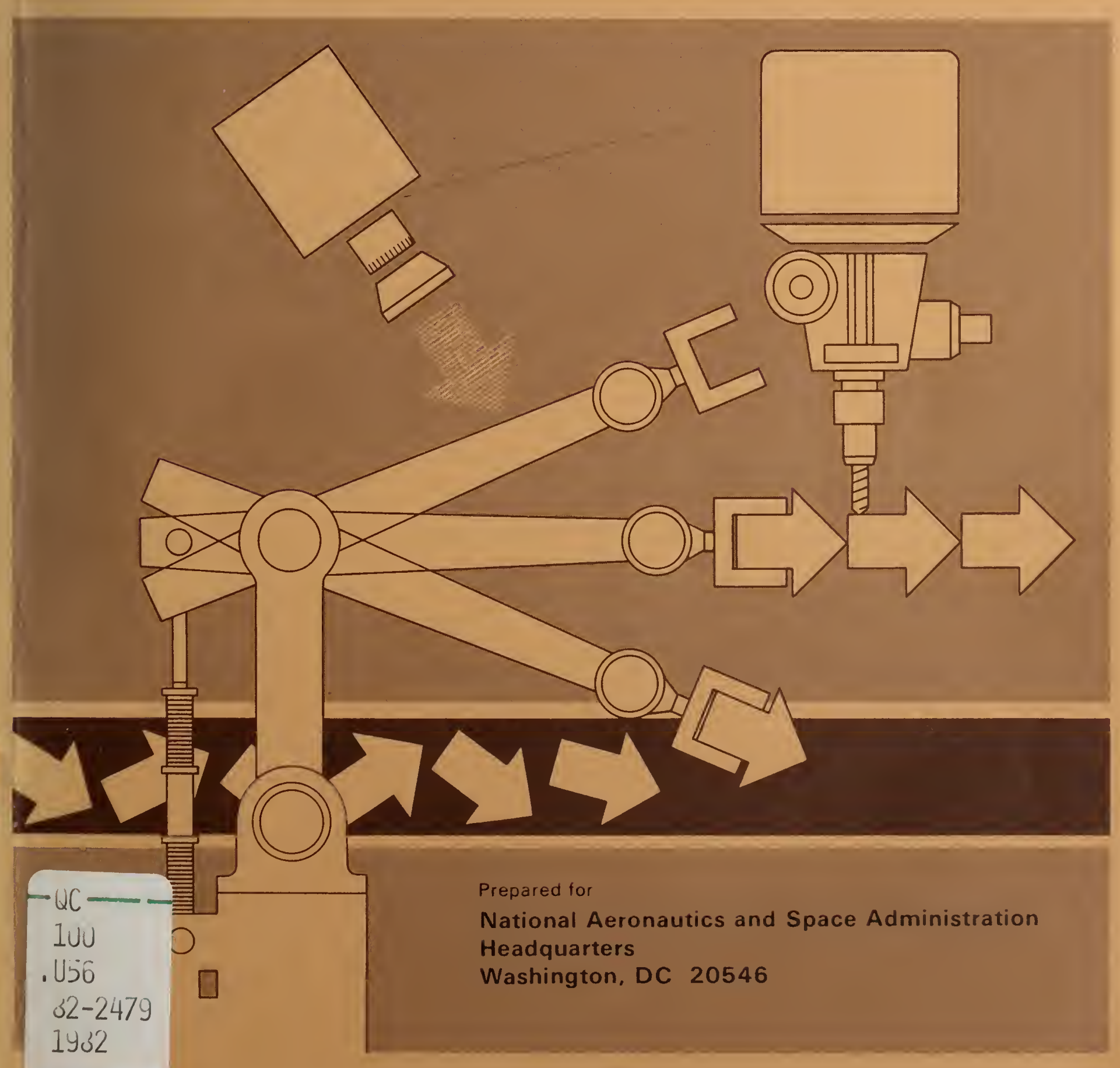





\section{AN OVERVIEW OF ARTIFICIAL \\ INTELLIGENCE AND ROBOTICS}

VOLUME II - Robotics

William B. Gevarter

U.S. DEPARTMENT OF COMMERCE

National Bureau of Standards

National Engineering Laboratory

Center for Manufacturing Engineering

Industrial Systems Division

Metrology Building, Room A127

Washington, DC 20234

March 1982

Prepared for:

National Aeronautics and Space Administration

Headquarters

Washington, DC 20546

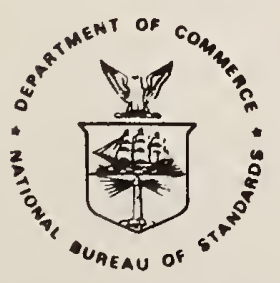

U.S. DEPARTMENT OF COMMERCE, Malcolm Baldrige, Secretary NATIONAL BUREAU OF STANDARDS, Ernest Ambler, Director 



\section{Preface}

This is the second volume of a two volume NBS/NASA report on an Overview of Artificial Intelligence and Robotics. This report is intended to be read by the interested technically-oriented layman, such as engineering managers, government funding officers, and others who desire an overall perspective of the field but are unable to obtain it from the highly technical and unintegrated literature in the field, or from the more flamboyant but non-technical feature articles in the popular press.

The report incorporates a summary of the basic concepts utilized in each of the many technical areas, a review of the state-of-the art, an indication of the organizations involved together with their funding sources and principal activities, research requirements, and a 5-10 year forecast of the emerging technology

As robotics is a very rapidly changing field - with new companies, products and researchers entering the field each month - a report like this can only be regarded as an imperfect snapshot in time, and would benefit from periodic updating. Thus, quantitative information shown in this report may perhaps best be regarded as indicative rather than authoritative. Despite such shortcomings, this report should be helpful in providing a base, for organizations and individuals in and out of the government, for planning future robotic research and development, applications and utilizations. 


\section{Acknowledgments}

I wish to thank the many people and organizations who have contributed to this report, both in providing information, and in reviewing the report and suggesting corrections, modifications and additions. However, the responsibility for any remaining errors or inaccuracies must remain with the author.

It is not the intent of the National Bureau of Standards to recommend or endorse any of the manufacturers or organizations named in this report, but simply to attempt to provide an overview of the robotics field. However, in a diverse and rapadly changing field such as robotics, important activities and products may not have been mentioned. Lack of such mention does not in any way imply that they are not also worthwhile. The author would appreciate having any such omissions or oversights called to his attention so that they can be considered for future reports. 
AN OVERVIEW OF ROBOTICS

Table of Contents

Page

I Introduction . . . . . . . . . . . . . . . . . . 1

II Primitive Functions Accomplished by a Robot . . . . . . . . 8

II Manipulator Arm Configurations . . . . . . . . . . . 10

IV Actuators . . . . . . . . . . . . . . . 12

V Mobility . . . . . . . . . . . . . . . . . 13

VI End Effectors . . . . . . . . . . . . . . . . 14

VII Control . . . . . . . . . . . . . . . . . . 15

VIII Sensor-Controlled Robots . . . . . . . . . . . . . 17

IX Robot Vision . . . . . . . . . . . . . . . . . 18

A. Methods for Determination of Pose . . . . . . . . 18

1. Range . . . . . . . . . . . . . . 18

2. Orientation ............... 18

B. Feature Extraction . . . . . . . . . . . . . 21

C. Object Recognition . . . . . . . . . . . . . 21

1. Template Matching . . . . . . . . . . . 21

2. Use of Edge and Region Statistics . . . . . . . . 21

3. Fourier Transform . . . . . . . . . . 22

D. Future Techniques . . . . . . . . . . . . 22

X Programming a Robot . . . . . . . . . . . . . 23

XI Kinematics and Dynamics . . . . . . . . . . . . 24

A. Coordinate Transformations . . . . . . . . . 24

B. Trajectory Selection . . . . . . . . . . 24

C. Dynamics . . . . . . . . . . . . . 25 
Table of Contents (cont.)

Page

XII Research Requirements . . . . . . . . . . . . . 26

A. Different Views . . . . . . . . . . . . 26

B. Synthesis of Needed Research . . . . . . . . . . 33

1. Manipulator and Actuator Design . . . . . . . . 33

2. End Effectors . . . . . . . . . . . . 34

3. Control ... . . . . . . . . . . . 34

4. Sensory-Controlled Manipulation . . . . . . . . 35

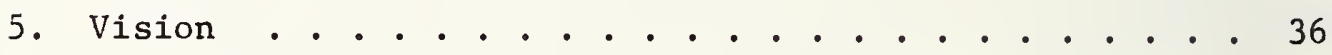

6. Tactile and Force Sensing . . . . . . . . . 37

7. Programming a Robot . . . . . . . . . . 37

8. Intelligence . . . . . . . . . . . . 37

a. Communication ............ . . 38

b. Knowledge Representation ........... 38

c. Planning . . . . . . . . . . . 38

9. Robot Mobility . . . . . . . . . . . 39

10. Modularity . . . . . . . . . . . . 40

XIII Commercially Available Robots and Components . . . . . . . 42

XIV Commercially Available Vision Systems for Robots . . . . . . 47

XV Current Robot Research . . . . . . . . . . . . 52

XVI Applications - Now and in the Future . . . . . . . . . 76

XVII The Expanding Robot Population . . . . . . . . . . 78

XVIII Future Directions . . . . . . . . . . . . . . . 86 


\section{ROBOTICS}

\section{Introduction}

Robots in use today are primarily machines with manipulators that can be easily programmed to do a variety of manual tasks automatically. The robot consists of one or more manipulators (arms), end effectors (hands), a controller, power supply, and - increasingly - sensors to provide information about the environment and feedback of performance in task accomplishment. The motivation for most current robotic development is industrial: to increase productivity, reduce costs, overcome skilled labor shortages, provide flexibility in batch operations, improve product quality and to free humans from boring, repetitive tasks or operations in hostile environments.

Table 1 gives the Japanese standard classifications for industrial robots (IR's) by input information and teaching method, and relates this to the U.S. classification by control method - non-servo or servo.

As indicated in Table 2, the Japanese are the world's largest user of robots. Counting all classifications of robots the Japanese had approximately 77,000 robots in use at the end of 1980 (Yonemoto, 1981, p. 1). Table 3 presents the Japanese robotic use by industry, based on robot costs. It seems that the electrical machinery and automobile industries are the largest users of robots. Less than $1 \%$ of IR's are utilized outside of manufacturing. Table 4 presents the 1979 Japanese usage by production process. It is apparent that over $60 \%$ of the usage is for moving or positioning a workpiece. This is reflected (see Table 5) in the predominance in 1980 robot production of the fixed sequence type of robots.

Of the many reasons for installing industrial robots, the most prominent ones are to increase productivity and reduce costs. A commonly used measure for determining the ecomonics of installing robots is the payback period. This is 


\section{Table 1 \\ Definitions and Classifications of Industrial Robots}

\author{
Japanese Industrial Standard JIS B0134-1979
}

Manipulator A device lor handling objects as desired without touching with the hands, and it has more than two of the motional capabilities such as revolution, out-in, up-down, right-lelt travelling, swinging or bending, so that it can spatially transpott an object by holding, adhering to, and soon

Robot

\begin{abstract}
A robot is delined as a mechanical system which has flexible motion lunctions analogous to the motion lunctions of lising organisms or combines such motion lunctions with intelligent lunctions, and which acts in response to the human will. In this context. intelligent lunctions mean the abilit! 10 pertorm at least one ol the follouing: judgnent, recognition, adaptation or lcarning.
\end{abstract}

\section{Classification by input information and teaching method}

Manual A maniputator that is directly operated by a man.
matnipulator

Siquence robot

Fixed sequence

A manipulator, the working step of which operates sequen tially in compliance with preset procedures, conditions and positions.

A seyuence robot as detined above, for which the preset intormation cannot be casily changed.

Variable A seyuence robot as delined ahose. for which the preset sequence intormation can be casily changed.

Playback robot

A maniputator that can repeat any operation alter being instructed by a man.

Numericaly A manipulator that can exccute the commanded opcration contrallea robot in compliance with the numerically loaded working information on c.g. position, seyuence and conditions Intelligent A robot that can determine its ow nactions through its sensing
robot

\author{
U.S. View
}

INDUSIRIAL. ROBOIS all hate armlike projections and grippers that perlorm lactory work customarily done by humans. The term is usually reserted lor machines with some lorm of huilt-in control system and capable ol stand-alone operation. But in Japan, it also includes manipulators operated by humans, either derectly or remotely.

\section{Classification by Servo Type}

\section{NON-SERVO ROBOTS}

A PICK-AND-PLACE ROBOt is the simplest isision accounting for about one-third of alt U.S. installations. The names comes from its usual application in matcrials handling. piching something trom one spot and placing it at another. Freedom of movement is usually limited to two or three discctions in and out. lelt and right, and up and doun. Ihe control system is electromechanical. Prices range from $\$ 5,000$ to $\$ 30.000$.

A SERVO ROBOL is the most common industral rohot because it can include all robots described below. The name stemstrom one or moreservomechanisms that enable the al $\mathrm{m}$ and gripper $t(0$ alter direction in midair without having to trip a mechanical switch. Five to seren directional movements are common, depending on the number of "joints." or articulations. in the robotis-arm.

A PROGRAMMABI.E ROBO 1 is a serio robol directed hy a programmable controller that memorises al sequence of arm-and-gripper moscments this routine can then he repeated perpetually. I he robot is reprogrammed hy leading its gripper through the new tash. The price range is $\$ 25,000$ to $\$ 90.000$.

A (OMPUIERIZED ROBOT is a serso modet run by a computer. The computer controller docs not hase to he laght by leading the arm-gripper through a routine, new instructions can be transmitted electronically. The programming for such "smart" robots may include the ahility to optimis, or improse, its work-routine instructions. Pricesstart at ahout $\$ 35.000$

A SENSORY ROBOI is a computerized ohot with one or more artalicial senses. usualls sight or touch. Prices for carly models start at ahout $\$ 75.000$.

AN ASSEMBI I RO13OI is a computeried rohot, prohahly a sensory model, designed specilically for anemhli-line johs. For light. battch-manufacturing applications, the arm's design nay he lairly anthroponorphic 
Table 2

IRs in Operation

(As of the End of 1979)

\begin{tabular}{|c|c|c|c|}
\hline Japan & 14,000 Units & $(69 \%)$ & $T$ \\
\hline United States & 3,255 & $(16 \%)$ & 一 \\
\hline West Germany & 850 & & \\
\hline Sweden & 600 & & Total \\
\hline Italy & 500 & & $(100 \%)$ \\
\hline Poland & 360 & $\begin{array}{l}\text { Western } \\
\text { Europe }\end{array}$ & \\
\hline France & 200 & $\begin{array}{l}3,013 \\
(15 \%)\end{array}$ & \\
\hline Britain & 185 & 1 & \\
\hline Norway & 170 & & \\
\hline U.S.S.R. & 25 & & \\
\hline Belgium & 13 & & \\
\hline
\end{tabular}

(Note) Manual Manipulators and Fixed Sequence Robots are not included.

Source: Sadamoto, 1981, p. 52. 
Table 3

Principle Users of Industrial Robots in Japan

\author{
Share in 1980 \\ (Based on Value)
}

\begin{abstract}
Electric Machinery Industry
Automobile Industry

Plastic Moulding Products Industry

Metal Working Industry

Metal Working Machinery Industry

Steelmaking, Textile, Chemical,

Shipbuilding and Misc.
\end{abstract}

$36 \%$

$30 \%$

$10 \%$

$4 \%$

$15 \%$

Source: Yonemoto, 1981, p. 2 
Table 4

JAPANESE ROBOT USAGE BY PRODUCTION PROCESS

\begin{tabular}{lc}
\hline Process & $\%$ of Total \\
\hline Loading \& Unloading & 40 \\
Transfer \& Sorting & 21 \\
Palletizing & 9 \\
Welding & 6 \\
Work Maintenance & 4 \\
Assembly & 3 \\
Spraying & 2 \\
Other (Including \\
$\begin{array}{l}\text { Pouring, Screwing, } \\
\text { Riveting, etc.) } \\
\text { Total }\end{array}$
\end{tabular}

Source: Research Div., Long-Term Credit Bank of Japan, 1981 , p. 28. 
Table 5

JAPANESE PRODUCTION OF ROBOTS BY TYPE IN 1980

\begin{tabular}{|c|c|c|}
\hline Type & Unit & $\begin{array}{c}\text { Value } \\
(\$ \text { Million })\end{array}$ \\
\hline Manual Manipulators & $1,940(10 \%)$ & $13(4 \%)$ \\
\hline $\begin{array}{l}\text { Fixed Sequence } \\
\text { Control Robots }\end{array}$ & $13,440(67 \%)$ & $104(31 \%)$ \\
\hline $\begin{array}{l}\text { Variable Sequence } \\
\text { Control Robots }\end{array}$ & $1,340(7 \%)$ & $43(12 \%)$ \\
\hline Playback Robots & $2,030(10 \%)$ & $71(21 \%)$ \\
\hline NC Robots & $990(5 \%)$ & $97(29 \%)$ \\
\hline Intelligent Robots & $130(1 \%)$ & $10(3 \%)$ \\
\hline & & Total $(100 \%)$ \\
\hline $\begin{array}{l}\text { Other Robot-Related } \\
\text { Devices }\end{array}$ & & 10 \\
\hline Total & $19,870 \quad(100 \%)$ & 348 \\
\hline
\end{tabular}

Source: Ogawa, 198I, p. 132. 
usually given (see for example, Simons, 1980, p. 32) as the cost of the robot and accessories (including fixtures, etc.) divided by the annual savings:

$$
\mathrm{p}=\frac{\mathrm{I}}{\mathrm{L}-\mathrm{E}}
$$

where $\quad \mathrm{p}=$ payback period in years

$I=$ total investment

$\mathrm{L}=$ total annual savings in labor

$E=$ total annual robot upkeep cost.

Typically, automation investments have required that the payback period be three years or less, with actual payback periods reaching as low as one year when multiple shifts are utilized. 
II. Primitive Functions Accomplished by a Robot

Industrial robots are primarily designed for manipulation purposes. The primitive actions imposed at the hand by the manipulator are:

1. Moving

- from point to point

- following a desired trajectory

- following a contoured surface

2. Changing Orientation

3. Rotation

Non-servo robots can provide a sequence of point to point (PTP) motions. For each motion, the manipulator members move full tilt until the limits of travel are reached. Thus they are often referred to as "bang-bang", "pick and place" or "limited sequence" robots. "Programming is done by setting up the desired sequence of moves and by adjusting the end stops for each axis" (Tanner, 1979, p. 7). The use of mechanical stops and limit switches yields good positional accuracy, which is typically repeatable to better than $\pm 0.5 \mathrm{~mm}$ (Simons, 1980 , p. 20) .

Servo-controlled robots can be designed to provide a sequence of PTP motions, with controlled intermediate velocities. They can also be used to follow a programmed trajectory or by using sensors to follow a contoured surface.

If we consider end effectors, the robot can also be made to grasp, push and pull, twist, use tools, perform insertions and assembly, and do other manipulations done by humans.

If sensors and appropriate computations are added, the cot can perceive, inspect, recognize, test and do many of the other perceptua. luctions now done by humans.

All applications require that the robot interact with nvironment in the execution of its programmed task. Thus the robot is of teslgned to 
switch machines on and off and to accept information from machines as to their status. The robot may also have provisions for accepting signals from a moving assembly line, so it can track it. Similarly, the robot may have interface provisions for tactile, visual or other sensory inputs for feedback control. 


\section{Manipulator Arm Configurations}

To accomplish these primitive actions, four basic configurations of manipulator arm designs have evolved:
(a) Rectangular
(Figure la)
(b) Cylindrical
(Figure 1b)
(c) Spherical
(Figure 1c)
(d) Anthropomorphic, articulated or jointed arm (Figure 1d)

These arms utilize both rotary ("revolute") and linear ("prismatic") joints, as appropriate, to accomplish their function. Six degrees of freedom (6 DOF requires 6 joints) are necessary to locate the end effector (hand) at any point and orientation in the work volume. More $\mathrm{DOF}^{\prime} \mathrm{s}$ are sometimes used to prevent interference of the arm with the work piece or other obstacles. As few as 2 or 3 DOF may suffice for a simple "pick and place" robot.

As indicated in Figure 1, only three DOF's are required to position the end effector. However for applications requiring a high degree of wrist flexibility, as many as three of the arms DOF's are located in the wrist. These DOF's are usually referred to (using aeronautical terms) as pitch, yaw and roll.

The basic four manipulator arm configurations can be combined in various ways to produce a bewildering set of manipulator combinations. These combinations can be further extended by employing angled arms and offsets. Often built-in mechanical linkages are added to do such things as constrain the motion of nominally articulated arms to cylindrical coordinates for ease of control.

In addition, the arms may be designed to be mounted on their sides, hung from the ceiling, or mounted on rails for mobility, to further multiply the range of installed configurations. 


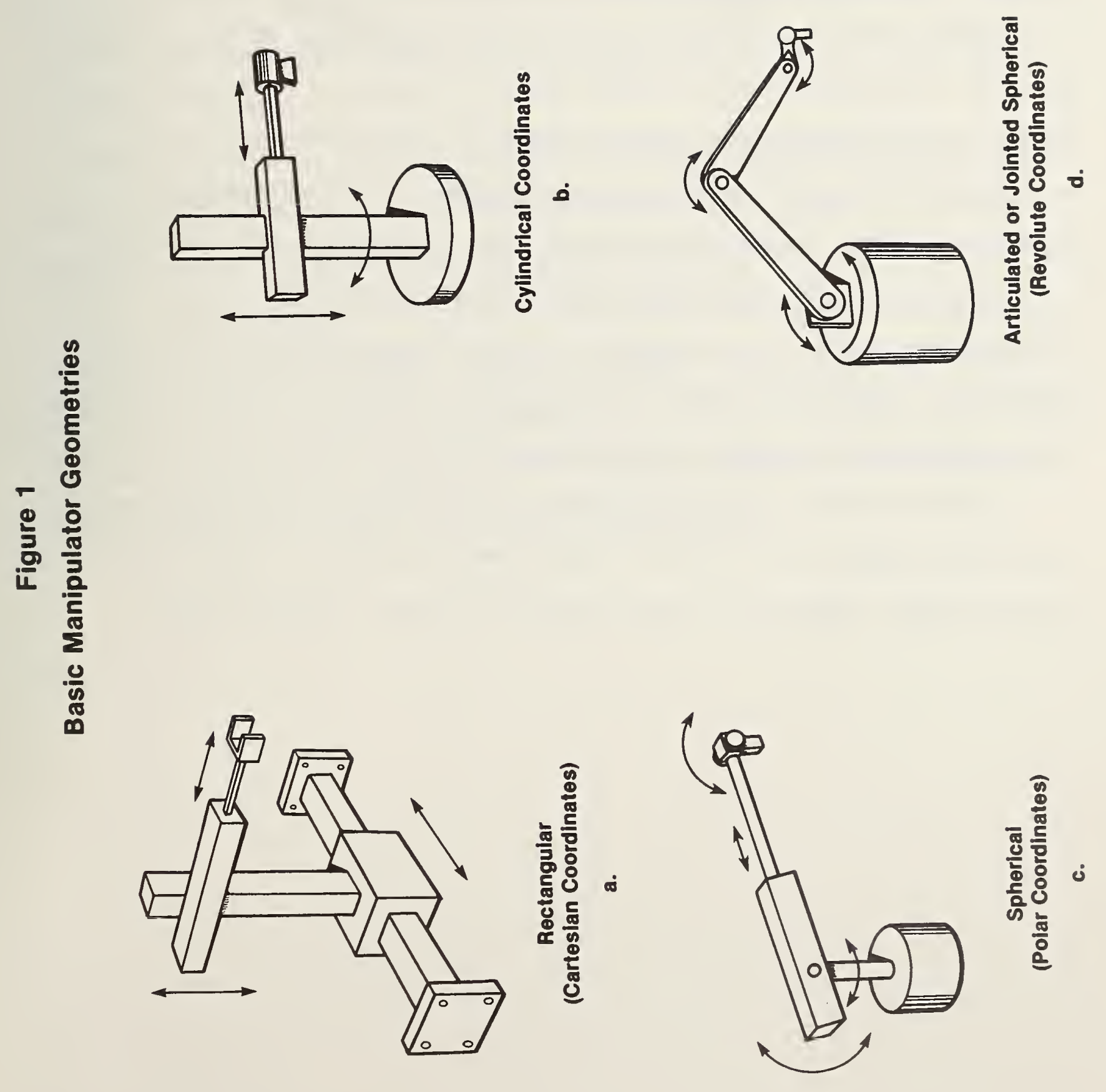


IV. Actuators

There are three major ways today of powering the actuators that move the manipulator joints: pneumatic, hydraulic and electrical. Pneumatic is simple and inexpensive but "squooshy" and is best used for "pick and place" robots whose trajectory motions are controlled by mechanical stops. Hydraulic actuation (currently the most popular system) is capable of high-power for a given size, but suffers from leakage problems as well as requiring pumps, storage tanks and other accompanying paraphenalia. Electrical-mechanical actuation is clean but doesn't offer good power to weight ratios. Stepper motors are inexpensive but sometimes lose pulses and therefore accuracy. D.C. torque motors are very reliable, offer good controllability, but can be expensive. Because the overall cost advantage of hydraulic systems diminishes with size, electrical drives are to be preferred for the small robot.

Actuators are the most problem-prone area of robotics. Thus considerable research is needed in this area to further improve reliability (robots have. an approximately $98 \%$ up-time these days) and to reduce costs and weight. 


\section{Mobility}

At present, most robots in industrial applications are fixed inplace or ride along rails, guideways or conveyors. Simple robot carts for transporting materials are now being used in industrial and commerical applications. Robot vehicles using wheels and treads have been researched by NASA for planetary exploration purposes.

Crawling robots, using their manipulator arms to grasp handholds, are being explored by NASA for use in constructing large structures in space. Walking machines are still in the experimental stage, with research going on at Ohio State University, Carnegie Mellon University (CMU), Tokyo Institute of Technology, and in the Eastern Block countries. Engelberger (1980, p. 63) states that "Practical robot devices with legs could have advantages in such applications as arctic transport, mining, agriculture, forestry, fire-fighting, explosive ordance disposal, unmanned ocean-floor surveys, and planetary exploration". 


\section{End-Effectors}

The hand or gripper, sometimes called the "end-effector", (attached to the robot wrist) can be a mechanical, vacuum or magnetic device for part (or object) handling or for tool manipulation. At present, most of the these interchangable devices are grippers which are simple open-and-close devices. The variety of tools and grippers that can be adapted for robot use is virtually unlimited (see for example, Engelberger, 1980, pp. 41-58). The end-effectors are usually unique to the robot application and thus customarily provided by the user, though several manufacturers offer a broad selection of devices for grasping parts that might be adaptable to the particular task being performed. Nevertheless, though hundreds of different special-purpose end-effectors now exist, the end-effector remains one of the major limiting factors in universal robot manipulation due to lack of dexterity and programmability of the hands. Extensive research and development is now underway to produce grippers that can handle a wide variety of part configurations. 
VII. Control

Control of robot arms ranges from highly repeatable open loop devices to servo-controllers that utilize external sensors in the control of robot actions.

Open loop devices may be as simple as a step sequencer and positionable mechanical stops for a pick and place robot, to more complex devices using stepper motors to reproduce a desired motion.

Servo-devices can use internal sensors, such as joint position sensors, or external information sensors such as force, proximity devices, and even vision (operating under computer control).

Servos operating only on internal sensors require very careful positioning of the work-piece (which can require expensive fixturing or feeding devices).

Servos utilizing data from sensing the external environment, require more complex processing of the signal, but yield much more flexible systems.

The controller, in addition to controlling the manipulator motion, often also serves as an interface to the outside world - coordinating the robots motions with machines and assembly lines and turning on and off machines that it is operating.

\section{A. Pick and Place Robots}

The simplest controllers are non-servo (open loop) devices that rely on sequencersand mechanical stops to control the manipulator end-point positions along each of the axes. These "limited sequence" robots are also referred to as "pick and place," "bang-bang," or "fixed stop" robots. These robots have no provision for trajectory control between the end points.

B. Programmable Robots

Programmable robots are servo controlled robots of two basic types: "pointto-point" and "continuous path." 
Point-to-point robots are directed by a programmable controller that memorizes a sequence of arm and end-effector positions. Hundreds of points may be memorized. The robot moves in a series of steps from one memorized point (set of point positions) to another under servo control, using internal joint sensors for feedback. Because of the servos, trajectory control between the memorized points is possible and relatively smooth motions can be achieved.

Continuous path robots do not depend on a series of intermediate points to generate a trajectory, but duplicate during the playback process the continuous motions recorded during the teaching process. Thus, these robots are used for painting, arc welding and other processes requiring smooth continuous motions.

\section{Computerized Robots}

Computer-controlled robots are capable of being programmed "off-line" using a high level programming language and do not have to rely on being physically taught.

\section{Sensory Robots}

These are computerized robots that interface to the outside world thru external sensing such as sight or touch. These "intelligent robots" are capable of adapting to a variety of conditions by changing their actions based on relating the sensed information to their goals or preprogrammed decision points.

E. Robots as Part of a Flexible Manufacturing System

A flexible manufacturing system (FMS) is a programmable batch-processing arrangement that contains programmable machine tools and transfer devices all under central computer control. When robots are used in such a system, the robot controller may itself be just the bottom layer of a hierarchical control system for the FMS (c.f. Topperwein, et al., 1980, pp. 96-105, or Albus, 1981A, pp. 261280). 


\section{Sensor-Controlled Robots}

Sensor-controlled robots are the first step on the path to truly intelligent robots - robots that can determine their own actions based on their perception and planning abilities.

The simplest versions of sensor-controlled robots utilize contact switching for stopping the arms and for opening and closing grippers. More sophisticated robots are now beginning to use touch, force and torque sensing. Forces and torques can be derived from stress measurements or from internal signals (e.g. derived from back EMF). Tactile information may be derived from deflection-induced resistance variations of a special sensing surface, or by various other ingenious approaches.

Work in France and at MIT on "artificial skins" with embedded arrays of touch sensors, opens the possibility of a robot eventually being able to determine position, orientation and identity of parts by touch alone. This may be particularly important for difficult assembly operations (Kinnucan, 1981). Proximity and range sensing are also now being considered.

Vision, the most complex of all the sensory modalities, is now beginning to find its way into robotic control. 
IX. Robot Vision

In the industrial manufacturing arena, to circumvent the problem of requiring that the workpiece be in a prescribed position and orientation (pose) for the robot to operate upon it, sensory systems are now beginning to be employed. Vision provides perhaps the most flexible approach to avoid all the fixturing that would be required to achieve a fixed pose.

Figure 2 lists the desired functions of a machine vision system to achieve fully flexible sensor-controlled manipulation. Figure 3 indicates potential applications for such a system.

A. Methods for determination of pose:

1. Range can be determined in four principle ways:

- Stereo

- Triangulation

- Active ranging (e.g. time of flight of light or sound)

- Using optical focusing.

2. Orientation can be determined by:

- observing the relationship of three (or more) known object points that are not all colinear in the viewing field, provided that the relative ranges connecting these points are known.

- Deriving surface normals using the intrinsic image concept (Barrow and Tennenbaum, 1981).

- Deducing it based upon the response of lighting on the object, utilizing known characteristics of the object. (This is simplified if structured lighting such as sheets of light are employed).

- Interferometry measuring the phase differences of an oscillating signal received at multiple points. 


\section{Figure 2}

Desired Functions of Machine Vision for Sensor-Controlled Manipulation in Industrial Manufacturing

- Recognition of workpieces/assemblies and/or recognition of the stable state where necessary.

- Determination of the position and orientation of workpieces/assemblies relative to a prescribed set of coordinate axes.

- Extraction and location of salient features of a workpiece/assembly to establish a spatial reference for visual servoing.

- In-process inspection -- verification that a process has been or is being satisfactorily completed.

Source: Rosen, 1978. 
Figure 3

Block Diagram of Potential Vision Applications in Robotics

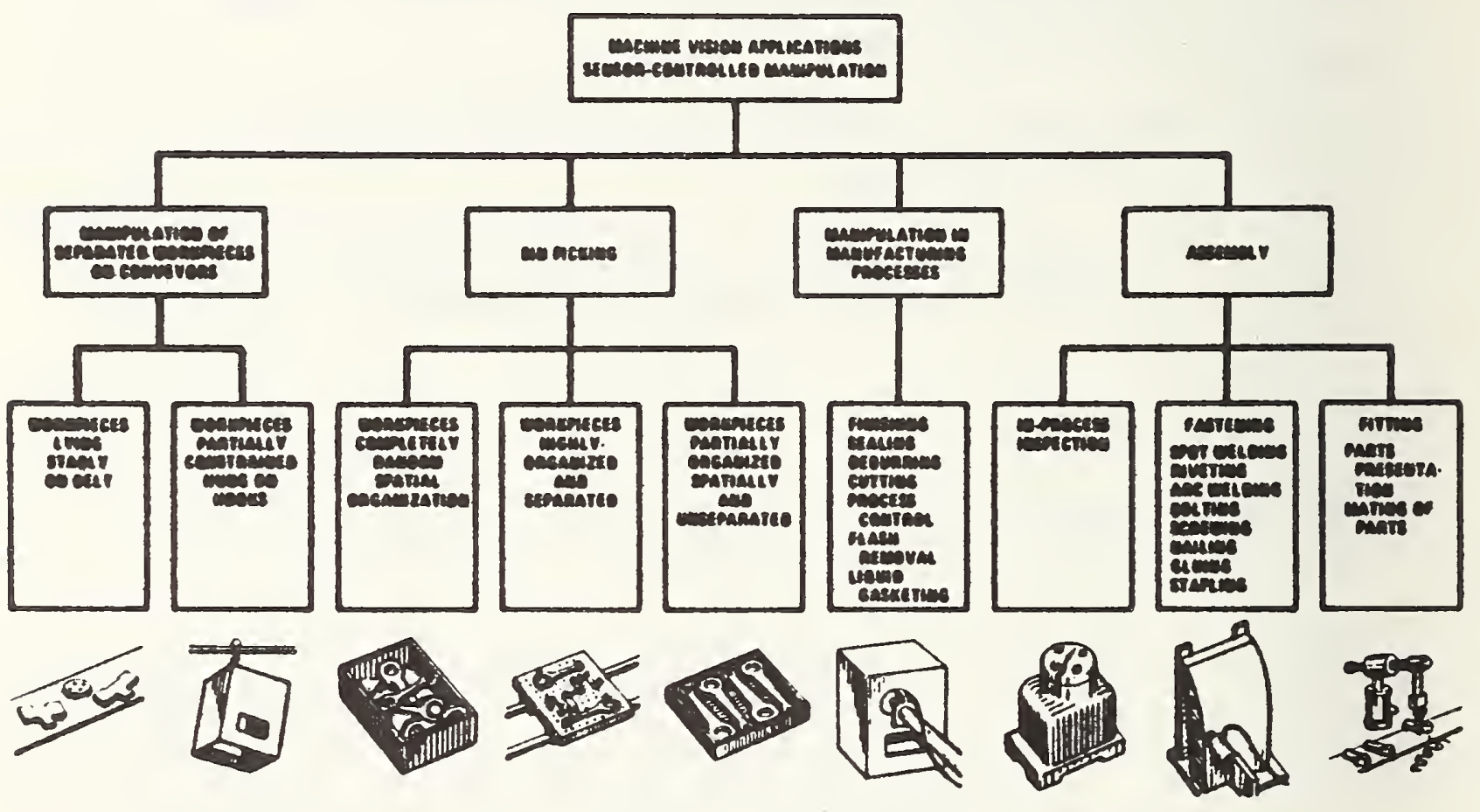

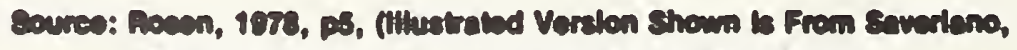

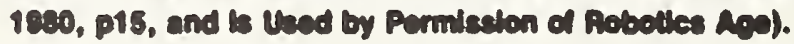




\section{B. Feature Extraction}

Though it is possible to operate directly on an analog output of a vidicon imager (by such approaches as optical correlation, or template matching), it is now fashionable to use solid state imaging arrays, such as CCD or CID devices, which directly provide points (pixels) in the image.

These pixels are then digitized by intensity levels (usually 2 to 16) so as to be put in a convenient form for operation upon by a computer. From this data, edges and regions are determined. Edges are considered to occur when there is an intensity gradient exceeding a selected threshold. These gradients are derived from intensity differences between adjacent pixels (of ten using an averaging scheme to reduce noise effects). Regions are grown by annexing ("clustering") adjacent pixels that are close to the same intensity level. Various schemes (heuristics) exist to connect lines having gaps, smooth irregularities, and remove discontinuities in regions (a11 resulting from noise in the image). The result (which can be considered as a form of data compression) is a reduced image that consists of edges and regions. Further data compression might be achieved by representing edges by sets of straight or curved lines (the ends and curvature of which are all that need to be known).

\section{Object Recognition}

Having determined edges and regions, it is possible using the methods of Section A to determine position and orientation. However, often it is necessary to determine which object is being observed from a collection of possible objects. This may be accomplished by

1. Template Matching: Using a stored image in the computer.

2. Use of Edge and Region Statistics: This may be curvature of edges, area moments of inertia, ratio of square of perimeter to area, number and/or location of holes or notches, etc. 
3. Fourier Transform: Determining the coefficients of the spatial Fourier transform and comparing them to the coefficients of known objects.

\section{Future Techniques}

In the future we may see:

- Greater use of direct range measurements - e.g. scanning laser radar, or LED's and photo diodes using phase or intensity measurements.

- Parallel processing to obtain feature extraction in real-time.

- Improved methods for determining edges and regions.

- Use of optical markings for recognition, for optical code reading or for determination of pose.

- Use of intrinsic image analysis - to determine surface orientation, depth, relationship of foreground to background, and texture.

- Scene analysis for less-structured situations. 


\section{Programming a Robot}

There are four primary methods for programming a robot:

- Physical-setup, in which the operator sets up programs by physically fixing stops, setting switches, arraying wires, etc. This is characteristic of the simpler robots.

Lead-through, in which the operator leads the robot through the desired positions and locations by means of a remote teach box. (These points are recorded and used to generate the robot trajectory during operation.)

Walk-through, where the robot arm is physically manipulated through the desired motions (which are recorded and then played back by the robot-control during operation).

- Writing a software program, which is then executed when desired.

The emphasis in programming research today is on software programming of computer-controlled robots. Work on sensor-controlled manipulation is extending the scope for programmability. Interacting with the robot by means of software, provides more flexibility then the other programming methods, and allows for conditional actions or flexible adaptations. Various high level robot programming languages such as VAL (Unimation) and AML (IBM) are now beginning to become available to aid in the software generation.

Simons (1980, p. 107) notes that software programs can be divided into two types: "In explicit programming, the user requires explicit instructions for every action the robot must take. In world modelling, the robot is more autonomous and can make decisions according to its knowledge. World-modelling systems, largely in the research stage, tend to require a considerable amount of computer power but are able to carry out complex tasks. The most important world-modelling languages are AL, AUTOPASS, and LANA..." 


\section{Kinematics and Dynamics}

\section{A. Coordinate Transformations}

If the arm is programmed by walking-thru, then it is simply necessary to record the simultaneous joint positions during the walk-thru. If the arm is led-thru, then in more sophisticated systems, that can operate in tool point, world, or other coordinate systems, it is necessary to do the needed coordinate transformations for each joint in order to obtain the desired end-effector orientation and position. This is particularly true when the arm is being programmed by writing software.

When the arm is controlled via feedback from a vision or other sensor, it is necessary to do coordinate transformations to convert the camera or hand coordinates to base or computer coordinates. For vision (or other sensor) control, the sensor interpretation and coordinate transformations need to be done in real time. As the mathematics for exact transformations requires time-consuming calculations, approximate simplifications have been developed to speed the calculations. In some systems, individual microprocessors are used to process the kinematics at each joint.

Note that arms are often designed so that the wrist motions are mechanically constrained to cylindrical or rectilinear coordinates to simplify control and reduce coordinate transformation requirements.

\section{B. Trajectory Selection}

For moving the end effector from one position (or point) to another, various schemes are possible for choosing the motions for moving the joints. Approaches for articulated arms include:

- Variations from preprogrammed paths.

The "dominant axis" approach: some joints may be allowed to adapt while others follow fixed movements. 
- All joint motions move proportionately relative to the slowest joint, so that all joint motions terminate at the same time.

Considerations of this sort become particularly important for off-line or real-time programming of computer-controlled robots.

C. Dynamics

At present, all robot arms are made relatively stiff so that structural flexibility is minimized (to promote repeatability). However, this requires stiff and usually heavy arms with high power actuators, lowered carrying capacity, and reduced speed. Research is now underway on the control of structurally flexible arms to help overcome these limitations, and in active control to control flexure for achieving on-line precision under load as during assembly or drilling operations. The 15 meter long Romote Manipulator System (RMS) for the Space Shuttle is probably the most extreme case of a structurally flexible manipulator thus far. 
XII. Research Requirements

A. Different Views

In considering research requirements it is very helpful to differentiate between near-term needs and far-term needs. Figure 4 indicates the near-term needs for improvement in IR's, as perceived by Japanese users. Note the emphasis is on robot flexibility and versatility of movement, speed, and ease of programming.

In observing how private enterprise is responding to the IR user desires, Umentani (1981, p. 81) indicates that the robot manufacturers most important targets for development include:

- reduced production costs

- smaller installation space requirements

- greater flexibility

- larger carrying capacities

- modular robots components to enable a building block approach to diversification of functions

- visual and tactile feedback and recognition systems

Table 6 lists the main research subjects being pursued by Japanese Robot Manufacturers. These may be regarded as relatively near-term. Note the correspondence with user desires in their emphasis on speed, flexibility and programing versatility.

As we move towards the longer term, we encounter robot research such as is being pursued in Japanese Universities and Japanese Government 
Figure 4

\section{JIRA User Survey of Desired Improvements in Industrial Robots}

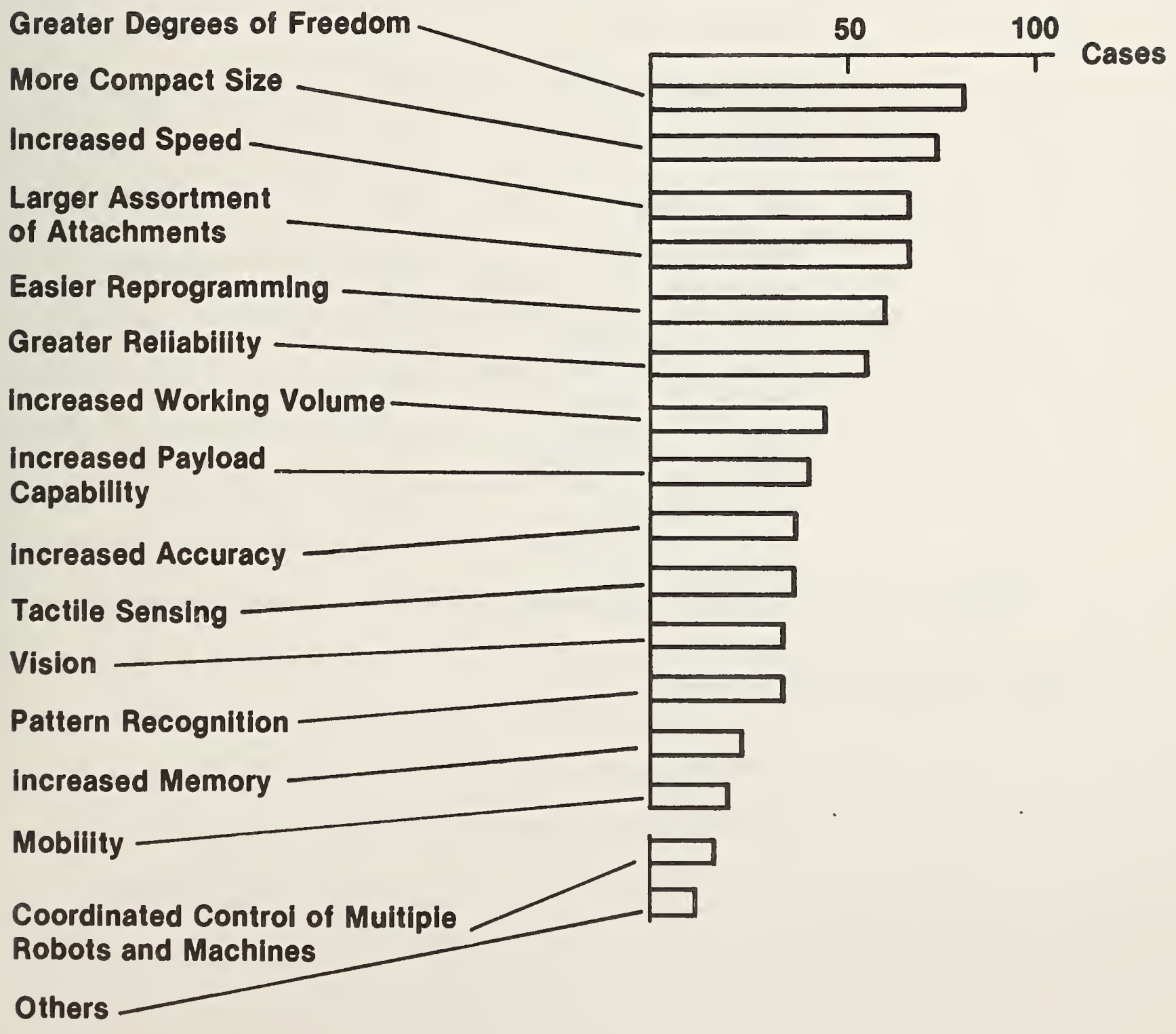

Source: Umentani, 1981, p. 84. 
Table 6

Main Research Subjects In IRs

1980 JIRA Survey of Japanese Robot Manufacturers

\begin{tabular}{|c|c|c|c|}
\hline $\begin{array}{l}\text { Order of } \\
\text { Importance }\end{array}$ & Subject & $\begin{array}{l}\text { No. of } \\
\text { Research } \\
\text { Subjects }\end{array}$ & $\begin{array}{l}\% \text { of } \\
\text { Total }\end{array}$ \\
\hline 1 & Increased Speed & 49 & 13.1 \\
\hline 2 & More Compact Size & 36 & 9.7 \\
\hline 3 & Computer Control & 32 & 8.6 \\
\hline 4 & Lighter Weight & 30 & 8.0 \\
\hline 5 & $\begin{array}{l}\text { Interchangeability } \\
\text { by Module }\end{array}$ & 25 & 6.7 \\
\hline 6 & Object Recognition & 19 & 5.0 \\
\hline 7 & Increased Payload & 17 & 4.6 \\
\hline 8 & Improved Actuators & 14 & 3.8 \\
\hline 9 & Self Diagnosis & 14 & 3.8 \\
\hline 10 & Adaptive Control & 14 & 3.8 \\
\hline
\end{tabular}

Source: Umentani, 1981, p. 98. 
Research Institutes. Here a 1980 JIRA research survey indicates (see Umentani, 1981, pp. 95-96) that their primary research topics (in decreasing order by number of research projects) are:

- control

- locomotion

- vision

- tactile sensing

- manipulators

- end effectors

- programming methods and tools

Figure 5 lists the desirable goals for future robots (from a U.S. vantage point) as seen by Engelberger (1980). He states (p. 125) that of the missing robotic attributes, the two most cruical ones are vision and tactile sensing. As indicated in Figure 6, this view is shared by the particpants in the NBS/RIA Robotics Research Workshop.

Kelley and Huston (1980), Birk and Kelley (1981), and Albus (1981B) have also attempted to come up with research requirements for future robots, though they did not attempt to prioritize them. Their requirements are summarized in Figure 7. In the following discussion we will combine these research needs into categories for ease of presentation. 


\section{Desirable Goals for Future Robots}

1. Rudimentary sense of vision to provide

a) recognition data

b) orientation data

2. Tactile sensing to provide

a) recognition data

b) orientation data

c) physical interaction data

3. Computer interpretation of the visual and tactile data

4. Multiple appendage hand-to-hand coordination

5. Computer directed appendage trajectories

6. Mobility

7. Minimized spatial intrusion

8. Energy conserving musculature

9. General purpose hands

10. Man-robot voice communication

11. Total self diagnostic fault tracing

12. Inherent safety (Asimov's Laws of Robotics)

13. All the capabilities above available for a price which allows purchase and operation within the traditionally accepted rules for economic justification of any new equipment

Source: Engelterger, 1980, p. 118. 


\section{Figure 6}

Recommended Distribution of U.S. Robotics Research Funds/Effort

$\begin{array}{lc} & \% \\ \text { Binary Vision } & 14 \\ \text { Gray Scale Vision } & 12 \\ \text { Off-line Programming } & 12 \\ \text { Control Systems } & 11 \\ \text { Touch, Force, Torque Sensing } & 11 \\ \text { End Effectors } & 10 \\ \text { Integration Into CAM Systems } & 8 \\ \text { Mechanical Systems } & 7 \\ \text { Simulation and Modeling } & 6 \\ \text { Safety } & 4 \\ \text { Mobility/Line Tracking } & 100 \% \\ \text { Others } & 1 \\ & \end{array}$

Source: NBS/RIA Robotics Research Workshop, 1979, p. 49. 
Figure 7

Basic Research Needs in Robotics (not prioritized)

Kelley and Huston (1980)

Manipulator Kinematics

Control

Locomotion

Sensing

Artificial Intelligence

Higher-Order Languages

Smaller Actuators

\section{Albus (1981B)}

Accuracy

Speed and Dexterity

Sensing

Control

Knowledge Representation

Programming (Higher Order Languages)

Standardized Interfaces (Modularity)

Mobility
Birk and Kelley (1981)

1. Intelligence

Knowledge Representation

Auto. Prob. Solving,

Decision Making, Planning

2. Control

Flexible Structures Control

Modeling

Real-time Sensory Control

Fault Tolerance, Monitoring and Repair

3. Actuation

4. Manipulation and Hands

Performance Evaluation

Kinematic Planning for Assembly

Speed

5. Dexterity

6. Locomotion

7. Sensing

Vision

Tactile

Real-time Computation

8. Programming

9. Adapation and Learning 


\section{B. Synthesis of Needed Research}

\section{Manipulator and Actuator Design:}

To achieve the higher speeds, flexibility, accuracy, efficiency and dexterity that is desired in future robots, additional research in manipulator arms are needed. For large manipulators and precision work, joint and arm structural flexibilities can be a problem. Therefore stiff, but lightweight arms are desirable to minimize this problem and to aid in increasing speed. However as variable compliance in different directions is often desirable to provide the "give" needed for inserting parts and other assembly operations, unique design approaches may be required.

At present, actuators are one of the more problem-prone areas of robots. In addition, actuator efficiencies are in the order of one tenth that of human musculature. Smaller, more reliable and efficient actuators and drive mechanisms, with high load to weight ratios, are needed for the high speed, lighter weight robots of the future.

For greater dexterity and less intrusion into the work-zone, it is also necessary to understand the mutual interdependence of end effector and manipulator kinematics. Also research on micro-manipulators is needed for applications to micro-electronics and biology.

A unified theory is needed on how to design an arm for smooth universal movements, satisfaction of functional requirements, and to provide the required load capacities throughout its motion spectrum. A standardized approach to performance measurement and evaluation is required to enable comparison of robots not only in such factors as working volume, load capacity and reliability, but also in aspects such as speed, smoothness and accuracy throughout their operating range. 
To help determine manipulator accuracy (now a limiting factor in off-line programming of open-loop manipulator operations), a universal stochastic model of mechanical errors of manipulators needs to be devised.

\section{End Effectors}

Umetani (1981, p. 110) states that "the most difficult barrier in industrial robot design... is the design of dexterity in hands and fingers." Thus, much work is needed to devise designs for general purpose hands (and the means to control them), such that the whole arm need not move to provide the desired dexterity. Because general purpose hands are not yet available, multiple end effectors may be required for a single application. This in turn requires some type of quick change wrist design.

\section{Control}

Kelley and Huston (1980) indicate that further research is needed on the basic robot problem: given the desired external or absolute displacement, velocity and acceleration of the hand, determine the optimal physical and internal motion parameters. (Birk and Kelley, 1981) state that procedures have been recently developed for efficiently obtaining and solving governing dynamic equations for robotic systems with flexible links and joints. However, optimizing the arm motion still presents problems of convergence and uniqueness (Kelley and Huston, 1980).

Though the repeatibility of arm positioning via open-loop (no external sensory feedback) robot control has been good, accuracy for initially positioning the arm via open-loop control has been poor. In addition, no efficient means of robot calibration has yet been determined. Thus it is important that more work be done on improving open-loop control accuracy. Accuracy degradation due to flexure can be a particularly troublesome problem when trying to perform precision operations under load, such as drilling without the aid of jigs. 
An important area of control not yet solved is control of structurally flexible manipulators. This problem, important to high speed manipulation with manipulators having high load to weight ratios, may require real-time simultaneous management of a large number of command and control variables. An associated problem with such manipulators may be the large changes in moments of inertia as the manipulator is extended and a load applied. Another problem associated with high speed manipulation, requiring additional research, is the generation of time-optimal trajectories.

An area for which little is known about ideal solutions, is the control of redundant-axis manipulators used to provide additional manuever capability.

Design of control systems for fault tolerance will become particularly important as robots become more autonomous.

Finally, lack of suitable strategies for control of multi-fingered hands is still one of the principle factors retarding design of dexterous hands. 


\section{Sensory-Controlled Manipulation}

One of the most desirable features for improving robot flexibility is sensory capability. Vision, the most popular U.S. robot research area, appears to be the most desirable sense for present and future IR's. Next in importance is touch.

To take full advantage of sophisticated sensory data, real-time control using sensors is needed. Hierarchical control may be the appropriate means to handle such data, though control logic systems such as pattern reference feedback logic may be appropriate in certain contexts.

In addition to vision and tactile sensing, dynamic control using force feedback is an important area of research. Also of increasing importance as robots become more autonomous, is proximity sensing as used before final contact and to avoid obstacles. Other sensors will increasingly have roles in inspection and in determining the type of material being observed. Research is needed in the use of models in sensory processing and interpretation.

It is also necessary to explore the tradeoff between the use of sensors and imposing more structure on the robot environment. As sensory control is perfected, the tradeoff will undoubtedly shift towards the direction of using sensors. 5. Vision

Vision becomes more important as the environment becomes less structured. Therefore vision is needed more for fire-fighting, household servants, robot explorers, etc., than for IR's. Vision can also reduce manipulator accuracy requirements, by making real-time adjustments practical.

At the current state of the art, additional research in recognition and geometric representation is needed. As greater capability is desired, three dimensional vision combined with world models and spatial reasoning will become important. Current 
3-D research in vision systems center on the use of range-finding, structured light, and binocular vision systems. Further-out, research is required in the analysis of image sequences (optical flow: shape from motion), intrinsic image analysis (determining shape from a single image by disambiguating the response to 1 ight), and improved methods to recognize objects in clutter. The bin-picking problem is a classic one in this latter area.

One of the most important research areas in vision is approaches to improve the speed of visual processing. This includes research in computational elements structured for visual processing, which includes parallel-processing CPU's, and special chips for edge-finding, Fourier analysis, etc.

\section{Tactile and Force Sensing}

What is needed is better use of contact sensing data. This includes better resolution in touch and force sensing. An important result could be the ability to recognize parts and to determine their relative position and orientation through such methods.

\section{Programming a Robot}

Programming by teaching is not practical for small lot production, particularly when sensory interaction is involved. Thus, improved techniques are needed for generating robot control data. These could include high-level programming languages, software debugging tools, world models, and the ability to directly utilize CAD data bases and sensory inputs. Robot simulation tools can aid in off-iine programming. Also needed are better geometric modeling systems. As robot usage advances, it would be desirable to produce aids for writing programs to orchestrate multiple arms and multiple sensors, and for systems with distributed control.

\section{Intelligence}

Plantier and Bodmer et a1. (1981, p. 63) assert, "Artificial Intelligence is the technological area which needs most to be developed and mastered to accelerate robot evolution." Birk and Kelley (1981) indicate that an intelligent robot is 
one capable of:

- receiving communication

- understanding its environment by the use of models

- formulating plans

- executing plans

- monitoring its operation

Thus research in all these areas is important.

Communication: Use of a natural language interface, or computer graphics or even voice commands would all be helpful in simplifying communication with a robot. In addition, intelligent aids for robot users to help plan and develop robot usage are also needed.

Knowledge Representation: A key ingredient in advanced robotics is knowledge representation. However, the tradeoff between control algorithm complexity and representation complexity needs to be explored. Sophisticated internal models of the environment are needed to generate expectations, to interpret sensory data, and for use in automatic generation of robot control data (such as for real-time decision-making).

Representations are also needed to enable qualitative reasoning about physics and space for use in planning and problem solving.

Parallel processing will be needed to make real-time modeling a reality. Planning: Automatic problem-solving or planning is one of the keys to future intelligent robots. Planning is even needed for acquiring information from sensors. Needed is research on ways to use large amounts of domain-specific knowledge to guide planning and responses to recognized situations.

One of the difficult, but important areas of research needed is in developing plans that deal with time. 
For certain tasks, the software for handling contingences is becoming excessive. Thus means for automatic monitoring and correction are needed. In addition, plan-monitoring and repair is also in need of research. It would also be useful to be able to store successful plans in categories so that they can be reused. In general, it is desirable that the system be capable of adaptation and learning.

Automatic assembly in non-highly structured environments is a key research area. Development of kinematic strategies for assembly is needed. Assembly could be aided by model-based generation of programs that use local sensory information in assembly tasks. Research is also needed for planning and orchestrating the actions of cooperating robot systems for assembly and other purposes.

Intelligent controls can be thought of as coupling control theoretic approaches with advanced AI methodolgies. To advance this area, better understanding of modular hierarchical structures is needed as well as how to generate hierarchical plans associated with such structures.

To make intelligent robots really useful, it is necessary to develop methods that will enable them to function in real-time (not having to pause for computation) with realistic computers.

\section{Robot Mobility}

For industrial robots tending machines, furnaces, etc., the robots are often in use only a fraction of the time, the remainder being in a wait mode. To make better use of the robots, machines are frequently arranged so that one robot can tend several machines. Sometimes this involves moving the robot (motion along tracks being the usual means). Locomotion is needed to further extend the working range and for use in hazardous environments and in remote locations. In many cases, a truly mobile robot would be preferred that can be used where needed. Mobile robots 
would be particularly advantageous in environments less structured than that found in factories, such as in the construction of ships, buildings and roads, in mining, and in undersea or space use.

New mechanical mechanisms, other than wheels, are needed for mobility over uneven terrain. However, mobility systems tend to amplify compliance and vibration problems (which can be minimized by careful design and the use of sensordriven control). Active suspensions are needed for uneven terrains, climbing, etc. For legged vehicles, the key problems are stability, control and optimal motion synthesis. In walking machines very little is known about the stability of various gaits. Advances are needed in the hierarchical control of multi-body systems. Efficient algorithms need to be developed for solving the governing dynamic equations.

If the mobile robot is to be supervisory-controlled, then optimal partitioning of the task between the operator and machine becomes an important research area.

\section{Modularity}

Further work is needed not only to develop modular manipulators, but also to enable integrated modular systems that can consist of a variety of robots, tools, sensors and computers all connected together. To do this, standardized interfaces are needed. It will be necessary to partition the control problem into modular components and to develop interface standards for communication between these components. An important goal is to be able to write an off-line program for one robot and be able to use it with a differently designed robot.

The 1980 NBS/Air Force ICAM Workshop on Robot Interfaces (1981) considered the following items for standardization.

simple sensor interface between simple peripheral devices and a robot control system. 
- Wrist interface between the robot wrist and the end effector.

- Complex sensor interface that covers vision, complex touch and other such sensors.

- Common robot control interface, providing robot independent trajectory descriptions.

- Robot Programming Languages

- Integration of robots into robot systems for automated manufacturing.

It was concluded that both the simple sensor and wrist interfaces were ready for standardization, but that it was too early in the development of the other areas to begin a standards effort at that time. 
XIII. Commercially Available Robots and Components

Engelberger (1980, p. 117) indicates that many of the attributes required to make industrial robots practical in an industrial environment are available today. These (see Figure \&) include good positioning repeatability, reliability, flexibility, easy programmability and adequate load capacity, all at a affordable price.

The rapid growth of industrial robots (roughly $35 \%$ per year) and the entry of new manufacturers and new products makes its inappropriate to try to list or even summarize all the robots currently available. However, the following are good sources of information to keep current with available robot products: - Robotics Age, a bimonthly magazine popularizing robots, P.0. Box 725, La Canada, CA 91011.

- Robotics Industry Directory published yearly by Robotics Age, P.0. Box 725, La Canda, CA 91011. This directory lists complete information on over one hundred different models of currently available robots, robot components and peripherals. It also provides information on robot distributors, robot research institutes and consultants in the robot field. Robot Systems and Products, providing a monthly new products update, is also available from Robotics Age.

- Specifications and Applications of Industrial Robots in Japan published by Japan Industrial Robot Association (JIRA), 3-5-8, Shiba Koen, Minato-ku, Tokyo, Japan. A 1982 edition is currently available. JIRA is a good source for all information on Japanese robots.

Robotics Today, a quarterly magazine on industrial robotics published by the Society of Manufacturing Engineers in cooperation with the Robot Institute of America, One SME Drive, P.O. Box 930, Dearborn, MI 48128. 


\section{Figure 8}

Robot Attributes Now Commercially Available

1. Work space command with six infinitely controllable articulations between the robot base and its hand extremity

2. Teach and playback facilities - realizing fast, instinctive programming

3. Local and library memories of any practical size desired

4. Random program selection possible by external stimuli

5. Positioning accuracy repeatable to within $0.3 \mathrm{~mm}$

6. Weight handling capability up to 150 kilos

7. Point-to-point control and continuous path control, possibly intermixed in one robot

8. Synchronization with moving workpieces

9. Interface allowing compatibility with a computer

10. Palletizing and depalletizing capability

11. High reliability -- with not less than 400 hours MTBF

12. All the capabilities available for a price which allows purchase and operation within the traditionally accepted rules for economic justification of any new equipment

Source: Engelberger, 1980, p. 117. 
The Industrial Robot, a quarterly magazine with a European orientation toward industrial robots, published by IFS Ltd., 35-39 High St., Bedford MK42 7BT, England.

An excellent recent guide to industrial robots for perspective users Sanderson, R. J. et al., Industrial Robots: A Summary and Forecast for Manufacturing Managers, 1982 - can be purchased from TECH TRAN Corp., 134 N. Washington St., Naperville, IL 60540 .

In addition, various robotic newsletters (such as "Robot News International," also available from IFS Ltd., "Industrial Robots International," available from Technical Insights, Inc., P.0. Box 1304, Ft. Lee, N.J. 07024; and the "Robotics Newsletter," available from Bache, 100 Gold St., New York, NY 10038) offering information on new robot products and investments have recently begun to appear. Datamation, Byte, Business Week, Time and other technical and popular magazines have also recently begun to have feature articles on robotics.

At the end of 1981, there were some 50 U.S. based firms marketing or preparing to market robots (Conigliaro, 1981), the leaders being:

- Unimation Inc. (projected to have $32 \%$ of the estimate $\$ 215$ million (3075 units) U.S. market in 1982) and Cincinnati Milacron (projected to have $25 \%$ of the U.S. market in 1982).

Several of the large U.S. auto, electrical and computer firms have been building robots for internal use and are now entering or considering entering the commerical robot market. 
Japan at the end of 1981 had over 130 different manufacturers producing robots, many for their own internal use. Table 7 presents the robot production by major Japanese manufacturers for the years 1980 and 1981 . Of the estimates by JIRA of 19,400 robots, valued at 77 billion yen, produced in Japan in 1980 , only $3 \%$ were exported.

In 1979 , approximately 2400 robots were sold in Europe. European manufacturers having a major share of this market include:

$$
\begin{aligned}
& \text { ASEA - Sweden } \\
& \text { Olivetti - Italy }
\end{aligned}
$$

The Eastern Block Communist countries have been moving in the direction of robots to make up for their serious labor shortages. Business Week (Aug. 17, 1981) reported that the Soviets plan to manufacture 40,000 robots by 1985 to counter not only the shortage of skilled labor, but also absenteeism associated with drinking. 
Table 7

Number of Robots Produced by Major Japanese Robot Manufacturers Note: The figures in brackets indicate approximate value.

\begin{tabular}{|c|c|c|c|}
\hline Company & $\begin{array}{c}1980 \\
\text { Achievement }\end{array}$ & $\begin{array}{c}1981 \\
\text { Target }\end{array}$ & $\begin{array}{l}\text { Major Product } \\
\text { Function }\end{array}$ \\
\hline $\begin{array}{l}\text { Kawasaki Heavy } \\
\text { Industries }\end{array}$ & $\begin{array}{c}450 \\
(\$ 22 \mathrm{M})\end{array}$ & $\begin{array}{c}650 \\
(\$ 31 \mathrm{M})\end{array}$ & $\begin{array}{l}\text { Spot welding } \\
\text { Arc-welding }\end{array}$ \\
\hline Yaskawa Electric & $\begin{array}{c}360 \\
(\$ 16 \mathrm{M})\end{array}$ & $\begin{array}{c}630 \\
(\$ 29 M)\end{array}$ & Arc-welding \\
\hline Hitachi & 150 & $\begin{array}{c}480 \\
(\$ 22 \mathrm{M})\end{array}$ & $\begin{array}{l}\text { Spot welding } \\
\text { Arc-welding }\end{array}$ \\
\hline $\begin{array}{l}\text { Mitsubishi Heavy } \\
\text { Industries }\end{array}$ & 120 & 240 & $\begin{array}{l}\text { Spot welding } \\
\text { Print-spraying }\end{array}$ \\
\hline Kobe Steel & $\begin{array}{c}120 \\
(\$ 7 \mathrm{M})\end{array}$ & $\begin{array}{c}200 \\
(\$ 13 \mathrm{M})\end{array}$ & $\begin{array}{l}\text { Arc-welding } \\
\text { Paint-spraying }\end{array}$ \\
\hline Star Seiki & - & $(\$ 13 \mathrm{M})$ & $\begin{array}{l}\text { Plastic mould } \\
\text { picking }\end{array}$ \\
\hline $\begin{array}{l}\text { Shinmeiwa } \\
\text { Industry }\end{array}$ & $\begin{array}{l}360 \\
(\$ 4 \mathrm{M})\end{array}$ & $\begin{array}{l}480 \\
(\$ 9 M)\end{array}$ & Arc-welding \\
\hline Fuji Electric & 130 & $\begin{array}{l}200 \\
(\$ 9 \mathrm{M})\end{array}$ & Inspection \\
\hline Fujitsu-Fanuc & $\begin{array}{l}480 \\
(\$ 4 \mathrm{M})\end{array}$ & $\begin{array}{l}600 \\
(\$ 7 \mathrm{M})\end{array}$ & $\begin{array}{l}\text { Machine processing } \\
\text { Assembling }\end{array}$ \\
\hline Sankyo Seiki & - & $\begin{array}{c}300 \\
(\$ 4 \mathrm{M})\end{array}$ & Assembly \\
\hline Nitto Seiko & - & $\begin{array}{l}120 \\
(\$ 3 \mathrm{M})\end{array}$ & Assembly \\
\hline
\end{tabular}

Source: August 1981 Survey (Survey Japan, 1981, pp. 210-211). 
XIV. Commercially Available Vision Systems for Robots

Present commercially available vision systems for use with robots are basically devices that generate and analyze 2D images. These systems recognize objects by their silhouettes. Principle current manufacturers of sophisticated computer vision systems are:

Machine Intelligence Corporation (M.I.C.)

Sunnyvale, CA

Automatix Inc.

Burlington, MA

Octek Inc.

Burlington, MA

M.I.C. Vision Module

This Vision Module is based upon prototype software and hardware developed at SRI under NSF and industrial affiliate support (see Gleason and Agin, 1979).

The Vision Module consists of a solid-state TV camera, a preprocessor interface and a LSI-11 microcomputer. The vision software, stored in the LSI-11 memory, includes the entire library of vision subroutines previously developed at SRI, several application programs (such as training-by-showing and execution of part recognition), as well as newly developed capabilities. The capability to develop application programs by calling the vision-library subroutines makes the Vision Module a general-purpose vision system. The Vision Module is intended for a variety of industrial vision applications such as inprocess inspection, sensorcontrolled manipulation, and visual servoing.

The Vision Module can recognize parts on the basis of their size and shape regardless of their position or orientation. The part (lying in one of its stable states previously used to train the module) is recognized on the basis of a set of shape descriptions, including area, perimeter, number of holes, length of major and minor bounding ellipse axes, first and second moments of area, etc., and various algebraic combinations of these.

The Vision Module operates by appropriately thresholding the image in the preprocessor to achieve binary silhouettes of the objects in the scene. A frame buffer stores the binary image (consisting of zeros and ones) to achieve timing 
independence between the camera and the controlling microcomputer. Each line is sequentially scanned and "run-length" encoded (i.e., edge points recorded where the pixels change from zero to one or vice versa). Each run-length segment on a line is matched against segments of the previous line to determine their overlapping relations hips. Using these relation ships, the program traces the appearance and disappearance of blobs (regions) as the image is processed from top to bottom. Only one line at a time of image data needs to be stored in the computer.

At the heart of the vision processing are connectivity analysis routines which segment the image into contiguous regions (called "blobs") even in the presence of noise. During the connectivity analysis, sequences of perimeter points are extracted. Using this blob boundary information, other desired parameters such as area, area moments, shape, position and orientation of the blob can be computed.

The system is trained by showing the object to the TV camera resulting in all potentially useful shape descriptions being automatically calculated and stored. Then the same object is moved and photographed several times and the mean and variance of these descriptors calculated and stored. This resulting set of means and variances, can be used as a "prototype" for that object or class of objects. New objects can then be recognized in either of two ways. One, by using a normalized nearest-neighbor method, where the best fit of the features of the new object to the set of prototypes is selected. Two, using a binary decision tree (which can be built by the Vision Module software upon command) recognition is done by measuring one feature at a time, and at each stage subdividing the recognition problem into two smaller problems until a single choice remains. The time to read in, process and implement recognition is in the order of one second. 
Complete vision systems cost from $\$ 30-40$ thousand dollars. M.I.C. also markets the VS-110 Machine Vision System version for real time inspection tasks.

M.I.C. which is currently rapidly expanding, is placing increased emphasis on turnkey systems, and improved man-machine interfaces. The problems of resolution speed and cost are also being vigorously attacked.

\section{The Automatix Autovision System}

The Autovision System (Rheinhold and Vanderbrug, 1980) also uses the SRI algorithms as its main base for vision processing and in many ways is similar to the MIC system. However, the Autovision System's preprocessor (Scheinman, 1981) has a pixel memory capable of storing several images at once, or several bits of grey level information, or any combination. The versatility of the system comes from the system's powerful AI-32 control processor, which with its 32 bit internal design and megabyte memory address space, can operate in parallel with the preprocessor and has the ability to interface with multiple preprocessors and various other input and output devices. The control processor operates under an Automatix developed operating system. Most of the system software is factory programmed in PASCAL, except where speed or compactness is so critical that assembly language is used.

The primary interface for the user is via the Automatix application language, RAIL, which is designed for the non-computer oriented user. This powerful and flexible robot programming language makes it possible to sequence the operations of the Autovision system so that the desired task can be performed.

\section{Octek Vision System}

Octek has several vision systems based on a circuit board developed in 1980. It can handle two high resolution solid state TV cameras with $320 \times 480$ pixel arrays. The system has an on-board microprocessor that can manipulate images at four frames per second. The system can handle a 16 gray level scale. 
There are four memory planes so that similarities and differences between images can be determined. The system relies on a Data General or DEC computer for computation. The basic circuit board costs about $\$ 4500$, with the cost of a complete vision system ranging from $\$ 16,000$ to $\$ 40,000$.

\section{KEYSIGHT AND CONSIGHT}

At General Motors, several different computer vision systems are now operational (Rossol, 1981). KEYSIGHT is an example of a system for inspection tasks in automobile manufacturing. It uses a low-resolution solid state camera to inspect for the presence or absence of valve spring cap keys on automobile engines. Ingeniously applying fairly standard computer vision algorithms for edge finding, etc., the system locates the center of the valve spring assembly and then, based on the keys being brighter than the holes they fit over, determines if the keys are present.

More interesting is CONSIGHT, an example of a robot vision system that uses structured light to detect the silhouette of passing objects. Using a robot arm, CONSIGHT transfers a moving stream of non-touching, randomly oriented parts from a moving conveyor belt to a predetermined location.

Structured light provides a means to deal with situations that require both high spatial resolution and fast response. It allows part geometry to be sensed directly, as opposed to being inferred through grey level picture processing.

CONSIGHT is logically partioned into independent vision, robot and monitor subsystems. When the vision subsystem has seen the entire object, it sends to the monitor the object's position and belt position reference value. The robot subsystem then executes a previously "taught" robot program to transfer the part from the belt to a fixed position. 
A single narrow and intense line from two parallel, separated sources is projected across the belt surface perpendicular to the belt's direction of motion. A linear array camera builds a conventional two dimensional silhouette imate of passing parts by collecting a sequence of these image strips. For each object detected, a small number of numerical descriptions is automatically extracted for part classification and position determination.

CONSIGHT is now commercially available, having been licenced to Unimation, Cincinnati Milacron, M.I.C. and Automatix. 


\section{Current Robot Research}

\section{In Japan}

Robot related research in Japan can be placed into three categories - research done by universities and research institutions, by industry, and by special government sponsored task forces. A 1980 JIRA survey found that a total of 88 research projects were then underway at universities and public and private research institutions. However unlike the U.S., there were no large-scale research efforts at the universities or technology colleges.

Areas of emphasis in research projects at Japanese universities and research institutions are (Hasegawa, 1981, pp. 162-163):

- increasing robot speed

- coordination of multiple arms

- dexterous robot hands with tactile recognition capability for automatic assembly

- sensory development for intelligent robots

- robot locomotion

- robot control and application software development

\section{In the United States}

Robot research in the U.S. is primarily aimed in the direction of making robots more intelligent and versatile, with vision research being given a high priority. Albus (1981B, p. 7) states, "Much remains to be done in sensor technology to improve the performance, reliability and cost effectiveness of all types of sensory transducers. Even more remains to be done in improving the speed and sophistication of sensory processing algorithms and special purpose hardware for recognizing features and analyzing patterns in space and time."

Robotic research efforts at U.S. universities (rough1y reflecting FY-82 funding) are indicated in Table 8. Note that the research is centered on greater 
Table 8A

Robotics Research

Institution: Stanford University

Principal

Researchers: Thomas 0. Binford, Bernard Roth, Robert Cannon, Larry Leifer

(23 Grad Students, 4 PostDocs)

Research Funding: Approx. $\$ 1,400 \mathrm{~K} /$ year from NSF, ARPA and NASA

Manipulation

- Control of flexible manipulators

- Control of multiple manipulators

- Design of three-fingered hand

\section{Perception}

- Robot Vision

- Stereo Mapping

- Special purpose VLSI for vision

- Segmentation

- Force sensing and control

Programming and Intelligence

- $\mathrm{AL}$ (arm language) one of the most advanced robot programming languages available today.

- ACRONYM system for geometric modeling and reasoning for modelbased vision and for programming robots.

- Work on CAD, resulting in a simulator for mechanical systems and robot arms, and for off-line programming.

Mobility

- A continuing program of navigation and perception. 
Table $8 \mathrm{~B}-1$

Institution: Artificial Intelligence Lab., M.I.T.

Research Funding: \$1.75M DARPA and ONR.

\section{Robotics Mechanisms and Control}

Principal Researchers: Hollerback, Seering, Mason, Pubrick, Salisbury, Asada, Lorenzo Perez, Brooks, Hillis,

\section{Manipulation}

Design of Dexterous Hands

- Tendon-actuated three-fingered hands (for use with PUMA) 1ighter, nimbler, more compliant.

- Controllers for tendon-actuated fingers and shoulders.

Manipulator Design

- Direct drive actuation

- Developed a recursive Lagragian formulation of the dynamics of manipulators.

- Developed a simulation for robot linkages and biological arms.

- Hybrid controller that allows the available degrees of freedom to be divided into position servoing and force feedback servoing as needed to achieve the compliance required for assembly and operation under load.

\section{Perception}

Force and tactile sensors for automating compliant assembly task.

- High resolution tactile sensor.

- Strain gage force sensor.

\section{Programming and Intelligence}

Developing a high level language based on a geometric modeling system developed at the AI Lab.

- Allows errors to be modeled, as well as keeping track of spatial relationships in ways programmers find natural. 
- Connecting a PUMA directly to a LISP machine to be able to program it in this geometric modeling language - to improve robot speed, accuracy and interfacing with sensors and effectors.

II. Robot Vision for Parts Assembly and Repair

Principal Researchers: Brady, Grimson, Horn, Larson, Nishihara, and Poggio.

Perception

Acquire possibly overlapping laminar workpieces off a textured background.

- Real time edge detection carried out in hardware using a camera developed at M.I.T.

- M.I.T. constructed frame grabber provides a interface to commercially available area array cameras for real time processing of image files.

Utilize 3D vision for guiding the acquisition of objects from a bin of parts.

- Photometric stereo to determine local surface orientation.

(1) Using multiple light sources and assuming Lambertian reflectance.

(2) Use of diffuse light sources to determine layout of scences containing specular objects.

- Binocular stereo vision utilizing matching of detected edges to obtain depth. 


\section{Table $8 \mathrm{~B}-2$}

Institution: Mechanical Engineering Dept., M.I.T.

Principal Researchers: Thomas B. Sheridan, Nam P. Suh, Nathaniel H. Cook, Neville Hogan, (10 grad. students)

Research Funding: Approximately \$500K/Yr. from NOAA, ONR, NSF and NIHR.

I. Use of Robotics (Teleoperators) Underseas

\section{Manipulation}

Teleoperators under computer control.

\section{Perception}

Tactile sensing for oceanbottom operations.

Measurement arm attached to base of robot to subtract out base motion.

Vision tradeoffs of video frame rate, resolution and number of gray scale levels.

II. Upper Extremity Prosthetics

- movement control

- adaptive control stiffness 
INSTITUTION: Robotics Institute, Carnegie-Mellon University

DIRECTOR: Raj Reddy

$\begin{aligned} & \text { RESEARCHERS: } \quad 15 \text { Faculty } \\ & 6 \text { Research Associates } \\ & 18 \text { Graduate Students } \\ & 23 \text { Staff }\end{aligned}$

RESEARCH FUNDING: Approx. \$4 M/year from Westinghouse, Digital Equipment Corp, ONR, DARPA, NSF, and other industrial sponsors.

\section{Manipulation}

- Direct drive rare-earth magnet electric actuators for manipulator joints

- Multi-processor control systems

- Dexterous end effectors for handling compliant parts

\section{$\underline{\text { Perception }}$}

- Laser range sensor

- Proximity sensors

- Binary and gray scale image analysis and understanding

- Touch, force, pressure, vibration, temperature, and chemical sensors

- 3D sensors

\section{Mobility}

- Mobile cart

- Gait and legged motion analysis

\section{Manufacturing}

- Factory of the Future Project

- integrated factory system

- research testbed for manufacturing problem

- Intelligent Factory Management System

- Job-shop planning and scheduling

- Factory modelling and analysis

- Flexible user interfaces

- Flexible machining

- multiple robot and machine integration and control

- Flexible Assemb1y

- multiple robot and sensor integration and control

- multiple processor controllers

- electronic assembly

\section{Programming and Intelligence}

- Knowledge representation

- Problem-solving techniques for planning and scheduling 
Table 8D

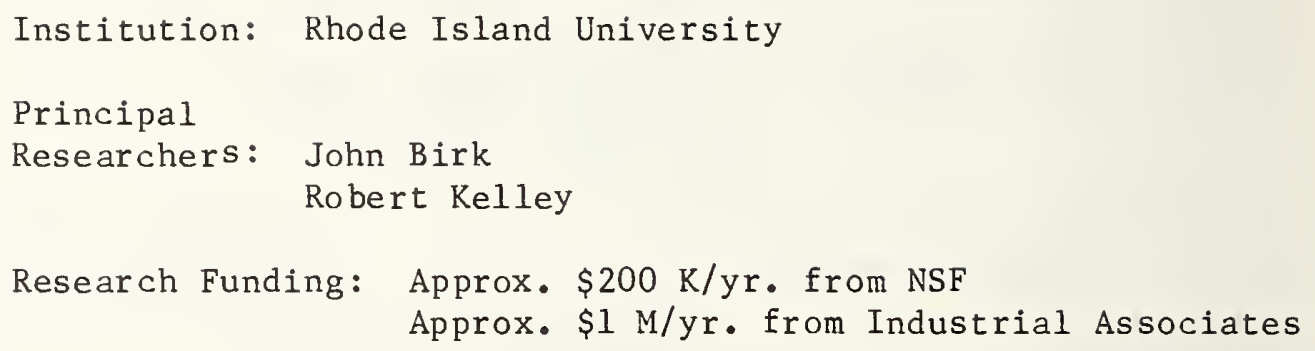

Manipulation

- Dexterous end effectors

- Articulated hands (includes manipulation within the hand itself).

- Design methods for hands

\section{Perception}

- Visual Pose estimation

- Touch sensing

Programming and Intelligence

- Robot programming language

Manufacturing

- Successfully demonstrated bin-picking

- General methods to enable robots with vision to acquire, orient and trans port workpieces

- Design of production systems utilizing robots 
Table 8E

Institution: University of Florida

Principal

Researcher: Del Tesar (+10 faculty from 5 disciplines and 20 grad. students)

Research

Funding: Approx. $\$ 1 \mathrm{M} / \mathrm{yr}$. from DOE, NSF and State of Florida

\section{Manipulation}

- Human augmentation with real-time digital computer assistance (computer-based teleoperators)

- Robot geometry, kinematics and dynamics - to achieve high-level dexterity

- Control of structurally flexible manipulators

- On-line robot precision under load (for batch processing)

- Actuator modules - to enable construction of customized manipulators

\section{Programming and Intelligence}

- Hierarchical control in an unstructured environment - using force feedback assistance. 
Table $8 F$

Robot Research at Other Universities

\begin{tabular}{|c|c|c|c|c|}
\hline University & $\begin{array}{l}\quad \$ \\
\text { Yearly } \\
\text { Funding } \\
\end{array}$ & $\begin{array}{l}\text { Manipulation, } \\
\text { Perception, } \\
\text { Mobility } \\
\end{array}$ & $\begin{array}{l}\text { Programming } \\
\text { and Intelligence }\end{array}$ & Manufacturing \\
\hline Purdue & $\begin{array}{l}\text { 100K } \\
\text { NSF }\end{array}$ & - Robot Vision & $\begin{array}{l}\text { - Robot Control System } \\
\text { - Robot Programming } \\
\text { Languages }\end{array}$ & $\begin{array}{l}\text { - Modeling of } \\
\text { parts flow thru } \\
\text { in industrial } \\
\text { plants }\end{array}$ \\
\hline U. of Mass & $\begin{array}{l}300 \mathrm{~K} \\
\mathrm{NSF}\end{array}$ & & & $\begin{array}{l}\text { Design of parts } \\
\text { for automatic } \\
\text { assembly }\end{array}$ \\
\hline & & & & $\begin{array}{l}\text { Economic applic- } \\
\text { ation of assembly } \\
\text { robots }\end{array}$ \\
\hline U. of Mich & $\begin{array}{l}500 K \\
\text { State } \\
\text { of MI }\end{array}$ & $\begin{array}{l}\text { - To Implement a } \\
\text { new Robot Lab }\end{array}$ & & \\
\hline U. of $M D$ & & - Robot Vision & & \\
\hline $\begin{array}{l}\text { U. of } \\
\text { Rochester }\end{array}$ & $\begin{array}{l}200 K \\
\text { NSF, ONR }\end{array}$ & - Machine Vision & $\begin{array}{l}\text { Computer graphics } \\
\text { language - PADL }\end{array}$ & $\begin{array}{l}\text { - Automated } \\
\text { Manufacturing }\end{array}$ \\
\hline $\begin{array}{l}\text { U. of } \\
\text { Arizona }\end{array}$ & $100 \mathrm{~K}$ & - Teleoperators & & \\
\hline $\begin{array}{l}\text { Ohio State } \\
\text { (Robert } \\
\text { McGhee) }\end{array}$ & $\begin{array}{l}\text { IM NSF } \\
\& \text { DARPA }\end{array}$ & - Legged locomotion & $\begin{array}{l}\text { - Manipulator Dynamics } \\
\text { and Controls }\end{array}$ & \\
\hline $\begin{array}{l}\text { U. of IL } \\
U \text {. of PA } \\
\text { U. of WA } \\
\text { U. of Texas } \\
\text { R.P.I. }\end{array}$ & & $\begin{array}{l}\text { Small projects in } \\
\text { robotics and } \\
\text { related work }\end{array}$ & & \\
\hline
\end{tabular}


dexterity, improved sensory perception, higher-order robot programming languages, increased robot intelligence, and computerized manufacturing and assembly. As indicated in Table 9, the focus of robotics research in the U.S. non-profit research laboratories is on manufacturing, with emphasis on computerized planning, factory management, assembly and inspection.

Table 10 indicates robotic research efforts in commercial U.S. companies. The emphasis is on manufacturing, assembly and computer vision for part recognition and inspection.

Information on research and development in some of the U.S. companies specializing in sophisticated computer vision is indicated in Table 11. The emphasis is on vision for inspection and robot control, and on simplified command capability.

Table 12 gives an indication of the research activities of the principle U.S. robot manufacturers. Emphasis is on advanced control systems, improved programming techniques and mechanical design.

Though there is no central focus for robotics in the U.S. Government, several government agencies are involved in robotics research and a number of others are looking into applications.

Table 13 (roughly reflecting FY-82 funding) provides an overview of robotics research performed within the U.S. Government. In general, these activities can be viewed as exploratory research into robotic applications.

Table 14 presents an overview of robotics research (roughly reflecting FY-82 funding) supported by the U.S. Government. NSF primarily supports basic research, ONR supports a mixture of basic and applied research, while the V.A. is focussed on potential applications for the handicapped.

Table 15 (again roughly reflecting FY-82 funding) indicates some of the government supported robotics applications development in the manufacturing and rework areas. 
The various U.S. military services are considering future robotic research efforts that could lead to replacing humans, or leveraging their capabilities, for dangerous jobs or missions and for increased productivity.

It is estimated that the current (FY-82) overall U.S. Government support for robotics research and development is approximately 18 million dollars per year. Research in Europe and the Soviet Union

The Western Europeons are estimated to be spending two to four times as much as the U.S. on robotics and related research. (A recent survey of teleoperator and robotics research in Europe indicates that $\$ 10$ million per year is being spent in telemanipulation R\&D alone, (Plantier and Bodmer et al., 1981, p. 8).) As in the U.S., the emphasis is on making robots more intelligent and versatile. "Germany, Italy, Sweden, France, Switzerland and the United Kingdom, either in national research laboratories or in robot manufacturers, are presently the most advanced European countries in computer vision and sensor-based robots" (Plantier and Bodmer et al., 1981, p. 12).

No figures are available on robotic research in the U.S.S.R. and the Eastern Block Countries, but they appear to be making a strong effort in robotics in order to improve productivity and overcome labor shortages. However, the Soviets lack of ready access to digital and computer circuitry is hindering their research effects in advanced robots (Teschler, 1981, p. 48). 
Table 9A

\section{Robotics Research}

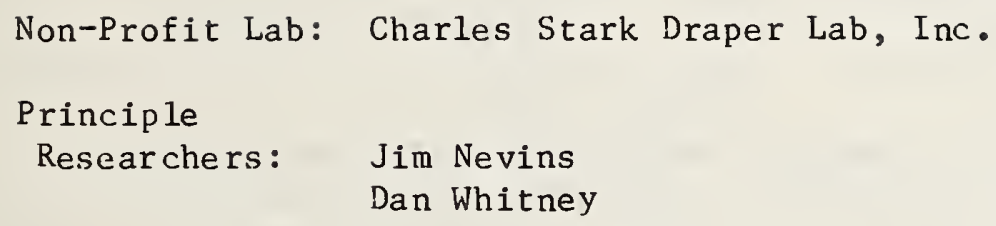

Research Funding: Approx. \$1 M/yr. from NSF and Industry

\section{Manufacturing}

- Part-mating science for assembly operations

- Sensory feedback

- Adaptive learning

- Passive compliance

-Models of assembly process

- Economic and configuration modeling for making choices among competing technologies in designing industrial systems

- Flexible assembly system design

- Operational strategies

- Product design for producibility

Applications, with industry, range from precision products with low annual volume to products with annual volumes in excess of several million. Techniques developed are also applicable to other environments, such as space, underwater, and medical. 
Table 9B

\title{
Robotics Research
}

\author{
Non-Profit Lab: SRI International \\ Principal \\ Researcher: David Nitzan \\ Research Funding: Approx. \$1 M/yr. from NSF and \\ Industrial Affiliates
}

\section{Perception}

- Machine vision for inspection and recognition

- Robot vision involving structured light, a combination of binary and gray-scale vision, and local features to distinguish overlapping parts

\section{Manufacturing}

- Vision-guided arc-welding

- Printed circuit board inspection

- Programmable assembly 
Table 10

Robot Research in Commercial U.S. Companies

Company
GM
Warren, MI
GE
Schenectady, NY

Westinghouse

Pittsburg, PA

\section{Research Activities}

- Robot vision systems for inspection and part transfer (KEYSIGHT, CONSIGHT)

- Automatic small parts assembly

- Flexible computer-controlled high-speed precise as sembly, to handle different versions of a one product family from a data base

- Evaluation of existing robots for use in GE manufacturing

- Robotics Research Laboratory evaluating use of commercial robots

- Supports productivity research at CMU ( $\left.\$ 1 M / y_{.}\right)$

- Adaptable Programmable Assembly System (APAS) ( $\$ 1 M / y r)$, cost-shared with NSF

- Supports Research on Teleoperators for Nuclear Power Plants at $U$. of Florida

- Developed own robots for its manufacturing operations

- Developed robot programming languages - AUTOPASS and EMILY

- Developed own robot for assembly and testing of hand calculators

Inst ruments

Mart in Marrietta Denver, CO $\left(\$ 3 M / y r_{.}\right)$
- Robotics research directed at DOD and NASA interests

- Autonomous devices

- Automated diagnosis/checkout

- Speed requirements of space manipulators

- Simplified high-speed coordinate transformations

- CAD robot program planning system

- Two arm coordinated manipulation (for DOE) 
Table 11

Near-Term R\&D in Sophisticated Computer Vision Systems

Automatix

Burlington, MA

Machine Intelligence Corp.

Sunnyvale, CA
- Robot Vision

- Robot Microcomputer Control Systems

- Robot Programming Language (RAIL)

- Commercial Robot Applications - arc welding

- Computer Vision Systems for Turnkey Inspection

- Materials Handling and Assembly Systems

- Univision System developed in cooperation with Unimation for the PUMA robot - programmed in VAL robot language. This is the first commerically-available seeing robot.

- Research in person/robot communication for non-computer oriented people. 
Table 12

Research Activities of U.S. Robot Manufacturers

Unimation

- Advanced control systems

- Calibration techniques

- Programming techniques

- Mobility systems

- UNIKA $^{\text {m }}$ vision for arc welding

Cincinnati Milacron

- New control system architectures

- Programming language

- Mechanical design

\section{Other Robot Manufacturers}

- Similar activities - all aggressively developing new and improved product lines. 
Table 13

In-House Government Robotic Research

Organization

National Bureau

of Standards

$\$ 1-1 / 2 \mathrm{M} / \mathrm{yr}$.

\section{Research Activities}

Standards

- Robot Interface Standands

- Robot Performance Measures

- Programming Language Standards for

- robot systems

- integrated computer-aided manufacturing

Advanced Concepts for

- sensory-interactive control systems

- modular distributed systems

- sensor interfaces to the control systems of robots and machine tools

- vision systems

\section{Focussed Application}

- Automated Manufacturing Research Facility

- planning

- scheduling

- routing

- inspection

- demonstration of a completely automated machine shop consisting of computer controlled NC machines served by robots and robot carts, producing mixed configurations of parts on demand 
Table 13 (cont.)

In-House Government Robotics Research

\section{Organization}

NASA

$\$ 1 M / y r$.

12 man years
Center

Langley Research Center Hampton, VA

Activity

- Robotics Laboratory to develop teleoperated and automated spacecraft servicing techniques

- Trajectory planning and multi-arm coordination

- Man-machine interface for remote systems

- Operating system for concurrent processes in a distributed computer network

- Robotics simulation

Marshall Space Flight Center Huntsville, Ala.

JPL

Pasadina, CA
- Research on end-effectors

- Man-machine interface for teleoperation

- Research in Hand-Eye Coordination

- Control of structurallyflexible manipulators

- Teleoperators

- 3 fingered hand with Stanford U.
Naval Ocean Systems Center

San Diego, CA $\$ 650 \mathrm{~K}$
Exploring application of robot and teleoperator systems

- submersibles

- land vehicles

- underwater manipulators

- stereo optic and acoustic vision

- remote presence

- autonomous robots - knowledge representation and automatic decision-making

- complex robot systems specification and verification 
Table 13 (cont.)

In-House Government Robotics Research

Naval Ocean Systems Center Hawaii

$\$ 300 \mathrm{~K}$
Exploring the use of telepresence (teleoperation with sensory feedback directly to the operator, giving a sense of being at the work site) for use in materials handling aboard ship. 
Organization: NSF

Washington, D.C.

Program (FY-81)

Production Research $\$ 2 \mathrm{M}$

(W. Spurgeon)

(Emphasis on robotics

for assembly)
Organizations Supported and P.I.

$\begin{array}{ll}\text { U. of R.I. } & - \text { Birk } \\ \text { C. N. K. Corp. } & \text { - Hayes } \\ \text { SRI } & \text { - Barnard } \\ \text { SRI } & - \text { Nitzan } \\ \text { Merrick Corp. } & \text { - Cook } \\ \text { Taylor Sys. Engr. } & - \text { Kerth } \\ \text { Stanford U. } & - \text { McCarthy } \\ & \text { \& Binford } \\ \text { M.I. Corp. } & - \text { Rosen } \\ \text { U. of Mass. } & - \text { Boothroyd }\end{array}$

U.C. Berkeley

Mechanical Systems

(A. Strauss)

$\$ 700 \mathrm{~K}$

(Emphasis on control, dynamics, kinematics, and design)

$\begin{array}{ll} & \text { - Dornfield } \\ \text { UCLA } & \text { - Dubowsky } \\ \text { U of FL } & - \text { Sandor } \\ & - \text { Hole } \\ \text { U. of Nebraska } & - \text { Schade } \\ \text { Rutge rs } & - \text { Lee } \\ \text { Stevens } & - \text { Tricano } \\ \text { Columbia } & - \text { Freudenstein } \\ \text { Ohio State } & - \text { Srinivasan } \\ \text { U. of Conn. } & - \text { Huston }\end{array}$

Organizations Supported and P.I.

U. of PA
Purdue
CMU
SUNY
U. of S. Carolina
U. of IL
Purdue
U. of Minn.
U. of IL
RPI
Yale

- Rozina

- Kashyap

- Sanderson

- Shapiro

- Cannon

- Ahu ja

- Funkunaga

- Wechsler

- Gose

- Saridis

- Narendra

\section{Activity}

Part acquisition using vision

Part Recognition

Auto. Visual $\mathrm{PCB}$ inspection M.I. applied to Industrial Auto.

Adaptive arc welding Adaptive arc welding Integrated Programmable Auto.

Natural Language

Economic applications

Digital Control of

Industrial Process

Control of arc welding

Dynamics of high speed

machines

Kinematic analysis

Nonlinear dynamic structual synthesis

Mechanism motions

Design of high speed

mechanisms

Optimum design of

mechanisms.

Forces in high speed

linkages

Control of machine tool

feeds

Multi-body dynamics

\section{Activity}

Scene understanding

Image modeling

Parallel signal processing

Edge detection in images

Auto signal processing

Dot pattern processing

Image feature evaluation

Texture analysis

Auto. scene analysis

Intelligent controls

Self-learning systems 
Table 14 (cont.)

U.S. Government Supported Robotic Research

Organization: NSF

Washington, D.C.

Program (FY-81)

Public Technology

(A. Schwarzkopf)

$\$ 450 \mathrm{~K}$

Computer Engineering (B. Chern)

$\$ 300 \mathrm{~K}$

Intelligent Systems

(Y. T. Chien)

$\$ 100 \mathrm{~K}$
Organizations Supported and P.I.

Westinghouse

- Abraham

U. of Rochester

CMU

VPI

U. of PA

- Voelcker \& Requicha

- Chang

- Shapiro \& Haralick

- Bajczy $\underline{\text { Activity }}$

Programmable assembly
Geometric modeling

Robot memory

Geometric reasoning

Scene understanding using active sensing 
Table 14

U.S. Government Supported Robotic Research (cont.)

Organization

Office of Naval Research Arlington, VA

$\$ 1.7 \mathrm{M} / \mathrm{yr}$.

(Marvin Denicoff)
Organization Supported

M.I.T

$\$ 250 \mathrm{~K}$

U. of

Rochester

$\$ 100 \mathrm{~K}$

M.I.T.

$\$ 300 \mathrm{~K}$

Applied Physics Lab John Hopkins Univ. $\$ 100 \mathrm{~K}$

Rehabilitation Engr. Center Stanford Univ. $\$ 200 \mathrm{~K}$ $\$ 700 \mathrm{~K} / \mathrm{yr}$.

Activities

- Fundamental

research in

- vision

- manipulation

- reasoning

- Autonomous Unmanned Underwater Vehicles

- Communication and negotiation among distributed robots

- Machine Vision

- Fundamental research in robotic vision, manipulation and reasoning (in cooperation with ONR)

- Robotic work station for quadriplegics

- Robotic aids for severely disabled individuals

- Supervisory voice and head-orient ation command of a PUMA robot

- Human/Machine Interface

VA Hospital - West Roxbury $\$ 50 \mathrm{~K}$

- Myographic wheelchair control

VA Hospital - White River Junction, N.H.

- Communication control aid 
Table 14 (cont.)

\section{Organization}

A.F.O.S.R.

(A.F. Off. of

Scient if ic

Research)

Bolling $\mathrm{AFB}$,

D.C.
Program

Manufacturing

Science

(Tom Walsh)

$\$ 2 \mathrm{M} / \mathrm{yr}$.
Organizations Supported \& P.I. Activity

Developing Educational

Research centers of

excellence
- Assembly in manufacturing 
Table 15

U.S. Government Robotic Applications Development

\section{Organization}

Naval Air Rework Facility

San Diego, CA

$\$ 3 \mathrm{M} / \mathrm{yr}$.

Air Force Materials Lab.

Wright Patterson AFB

Dayton, Ohio

$\$ 1 M / y r$.

U.S. Army Human Engr. Lab.

Aberdeen Proving Grounds, MD

Office of Manufacturing Technology DARCOM

\section{Activity}

- Development of robots to

- remove rivets and fasteners from airplane wings

- strip and repaint aircraft

- perform wing assembly

- Robotic applications in manufacturing (Part of ICAM)

- Formulating a plan for military applications of robotics

- Robot applications in manufacturing 


\section{Applications Now and in the Future}

Figure 9 indicates current and anticipated future use of robots in manufacture in Japan. Currently, machine tool processing is dominant, followed by welding, assembly, and plastic molding. In $\%$ of value, assembly, and measurement and inspection are expected to increase while spot welding, plastic molding and machining processes are expected to decrease.

Table 16 indicates current and 1990 estimates of major uses for industrial robots in the U.S. In general the same trends are visible in the U.S. as in Japan, with welding and materials handling being currently dominant, moving towards assembly being the dominant application in 1990.

A recent JIRA forecast of robot applications development, introduction and diffusion is shown in Figure 10. Observe that by 1985 it is anticipated that robots for assembly, inspection, reactor maintenance, cleaning and ocean development, as well as all phases of manufacturing, will be in commercial use, with diffusion relatively complete by 1990. In the last half of this decade it is forecast that construction and mining robots, robots for fire fighting and even robots to assemble soft goods like textiles will begin commercial diffusion. In the same time period, prosthetic arms and legs, and robots for use in patient care and other medical applications will become widespread.

In the late $1980^{\prime}$ s, robots for use in various military applications, such as use in dangerous missions and hostile environments are also expected to appear. Also in the late $80^{\prime} \mathrm{s}$, robots for use in servicing of space satellites are anticipated. In the $1990^{\prime} \mathrm{s}$, robots for use in the construction and assembly of large space structures and in space manufacturing are forecast. Starting around 1995, semiautonomous robots are foreseen for use on extra terrestrial surfaces for exploration, mining, materials processing, manufacture, and the construction, tending and maintaining of space installations. 
Table 16

Estimated U.S. Robot Order Trends By Usage

\begin{tabular}{lcc} 
& Through 1981 & 1990 \\
& $25-30 \%$ & $30-35 \%$ \\
$\begin{array}{l}\text { Materials handing, } \\
\text { including machine } \\
\text { loading and un- } \\
\text { loading }\end{array}$ & & \\
Assembly & $10 \%$ & $35-40 \%$ \\
Spot-Welding & $35-45 \%$ & $3-5 \%$ \\
Arc-Welding & $5-8 \%$ & $15-20 \%$ \\
Paint spraying & $8-12 \%$ & $5 \%$ \\
Other & $8-10 \%$ & $7-10 \%$ \\
\hline
\end{tabular}

Source: (Conigliaro, 1981, p. 6) 


\section{Figure 10 \\ Robot Development, Introduction and Diffusion}

\section{Painting}

Metal Parts Assembly

Machining

Casting \& Forging

Plating

Car Assembly

Home Appliances Assy

Agricultural Machinery Assy

Soft Parts Assembly

Warehousing

Inspection

Industrial Cleaning

Agriculture \& Forestry

Atomic Energy Development

Constructlon \& Mining

Medical Field

Prosthetic Arms \& Legs

Ocean Development

Fire Defense

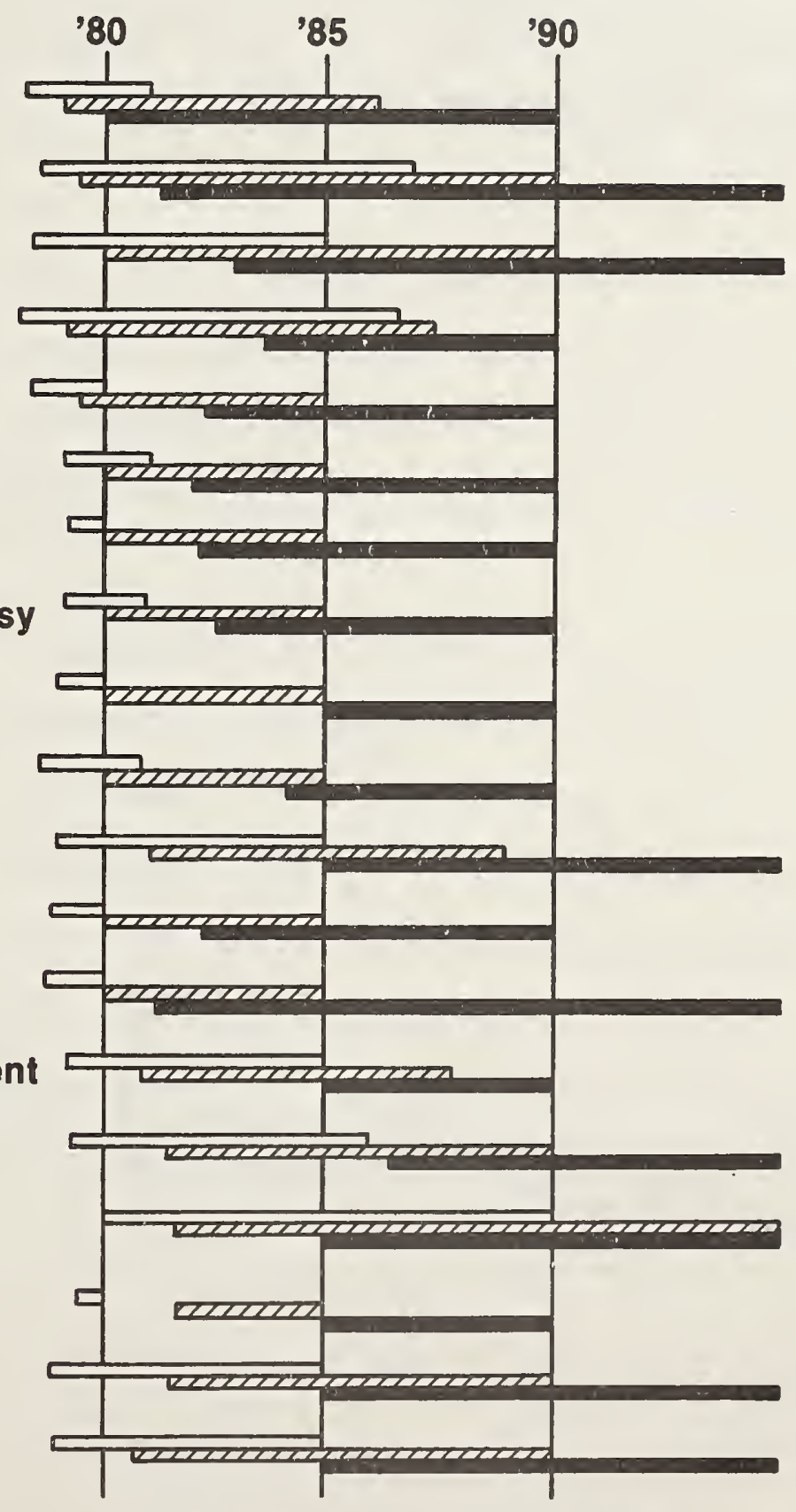

$\square$ Development

EIZA Introduction Into the Field

I Diffusion 
The general trend is toward robots with ever increasing intelligence and sensory capabilities. Engelberger (1980, p. 135) suggests that robots will eventually be entering the service industries, with such diverse applications as garbage collection and fast food preparation and dispensing. He even suggests that "...a [limited] household robot may be practicable before the end of the 1980's decade." 
XVII. The Expanding Robot Population

Table 2 presents JIRA's (The Long-Term Credit Bank of Japan, 1981, p. 52) estimate of the world's robot population as of the end of 1979 . The figures shown are for high-quality robots and exclude manually manipulated robots (teleoperators) and fixed sequence robots. Note that Japan with 14,000 robots has nearly $70 \%$ of the world's total, compared with $16 \%$ (representing a little over 3,000 units) for the U.S.

Figure 11 projects the U.S. robotics industry growth through 1990, when it is estimated that the U.S. will have roughly 100,000 IR's in operation, or some 30 times that of 1979. This estimate is predicated on major diversified companies - such as GE, Westinghouse, GM and IBM - entering the market as now appears to be happening.

Table 17 presents JIRA's forecast for the production of IR's in Japan through 1990, while Figure 12 indicates how this production will be distributed.

Integrating the results from Tables 2 and 17 and Figure 11, Figure 13 presents the composite forecast of the industrial robot population through 1990 . It appears that the world's robot population will pass $1,000,000$ in the early 1990 's, and will therefore have a major impact on the world's productivity.

A recent article in Business Week (Dec. 14, 1981) indicates that the robot pace is continuing to accelerate and even the figures quoted here may be very conservative. 


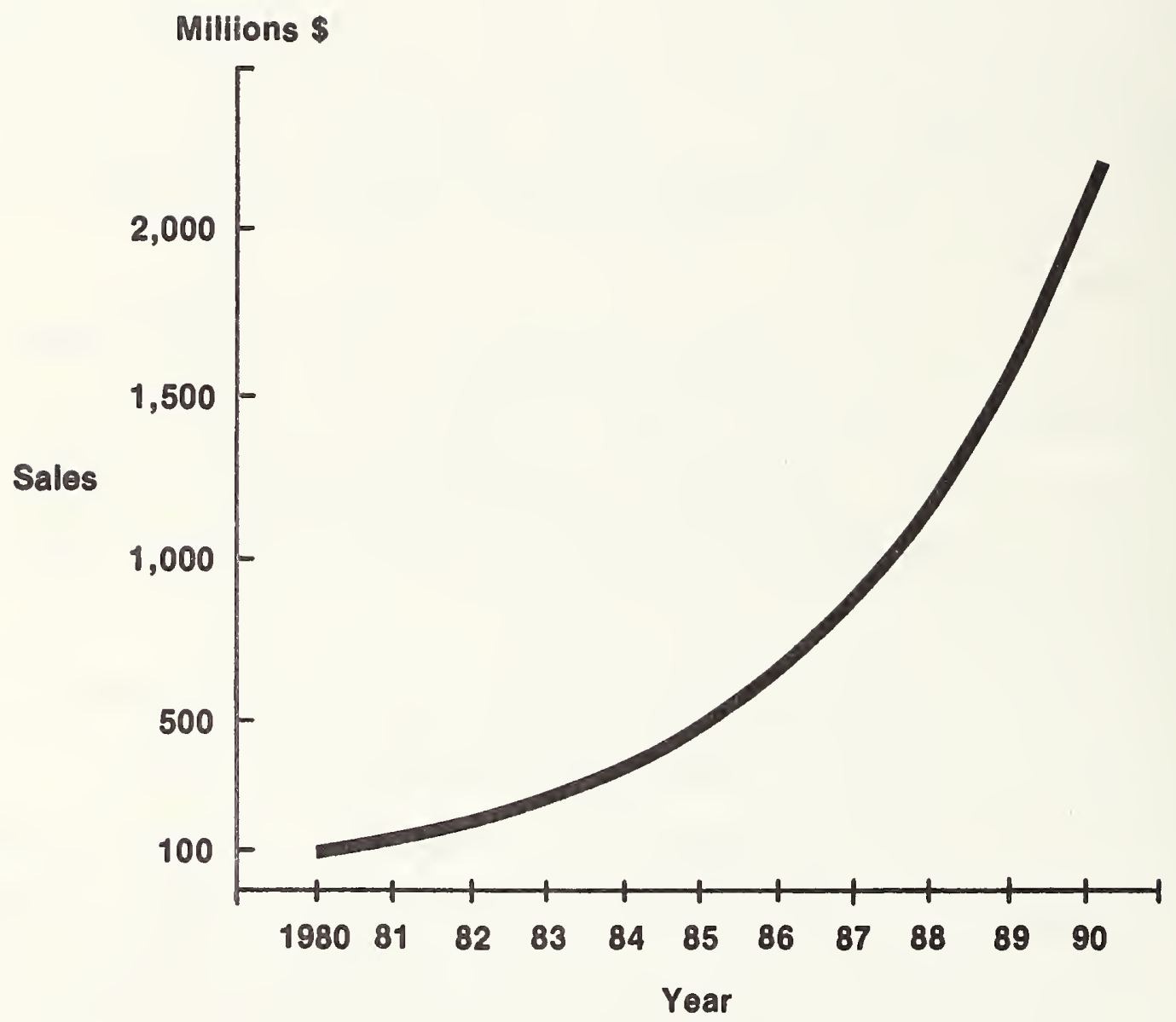

Figure 11

U.S. Robotics Industry Growth

1980.1990

Year

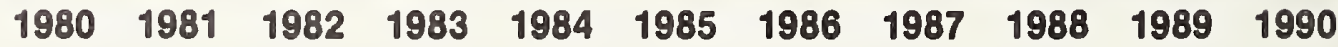

Estimatod Sajes

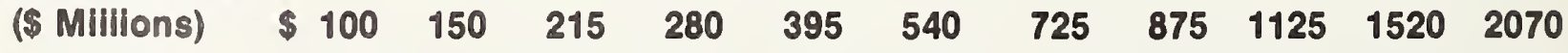

Estimated Units

Soid

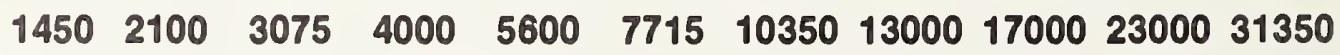
(Assumed Avg. Robot Cost Approx. \$70K Each)

Compound Growth of Revenue Per Year: $35 \%$

Source: Congliaro , 1981 
Table 17

Forecast of Aggregate Demand in Manufacturing for All Classes of IRs in Japan

(Unit \$ Billion)

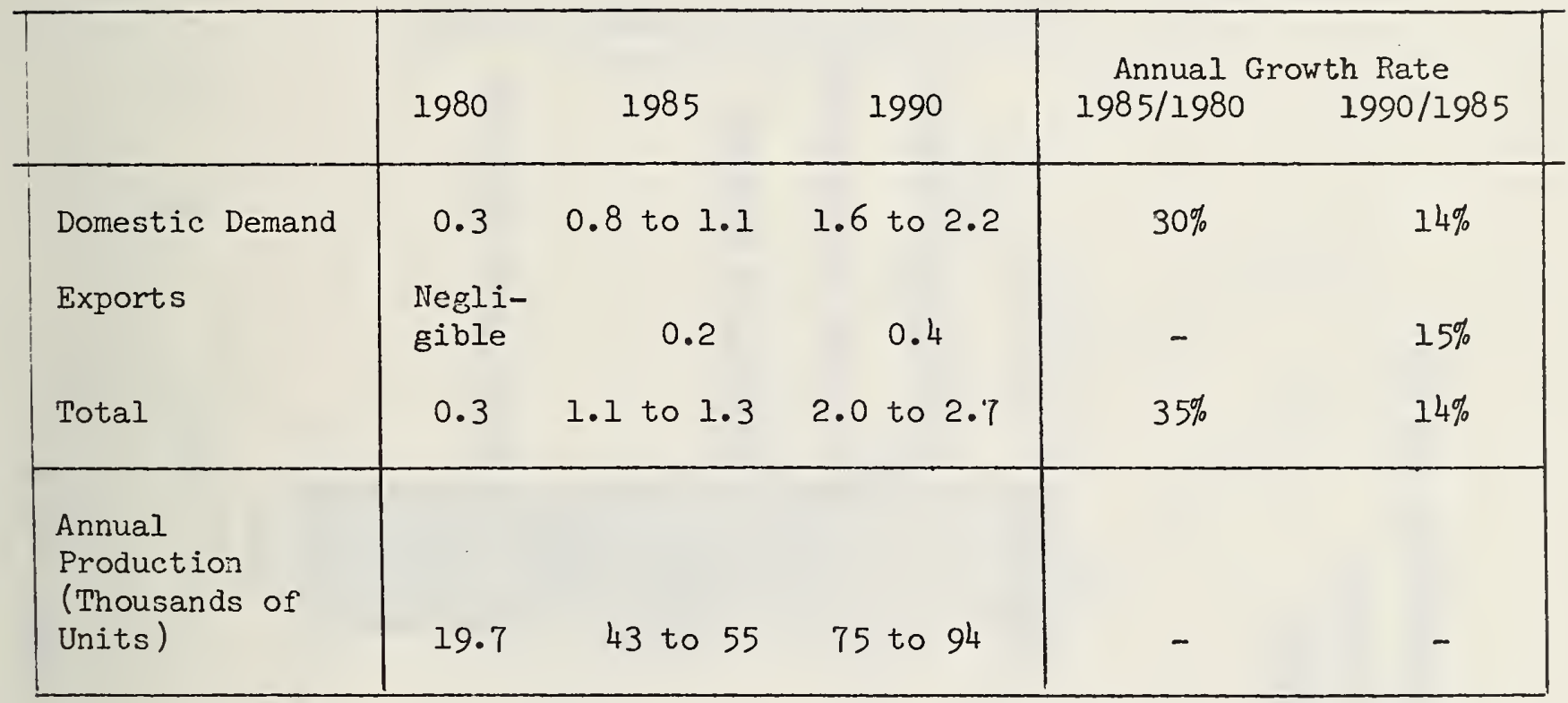

(Note) The export ratio is based on the JIRA target value of $20 \%$ in 1990.

Source: The Long-Term Credit Bank of Japan, 1981, p. 69. 

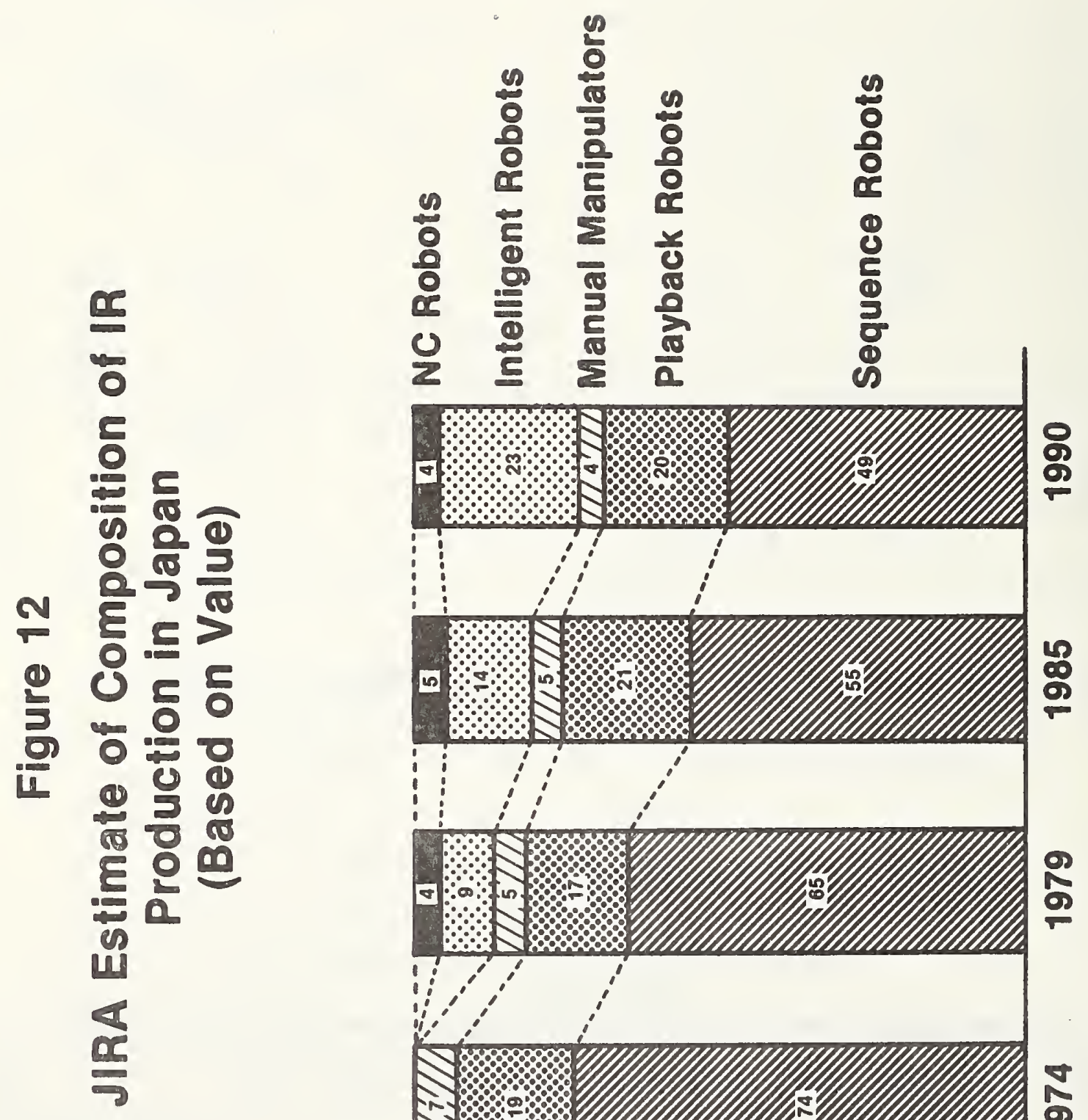

م.

$0^{\circ}$ 


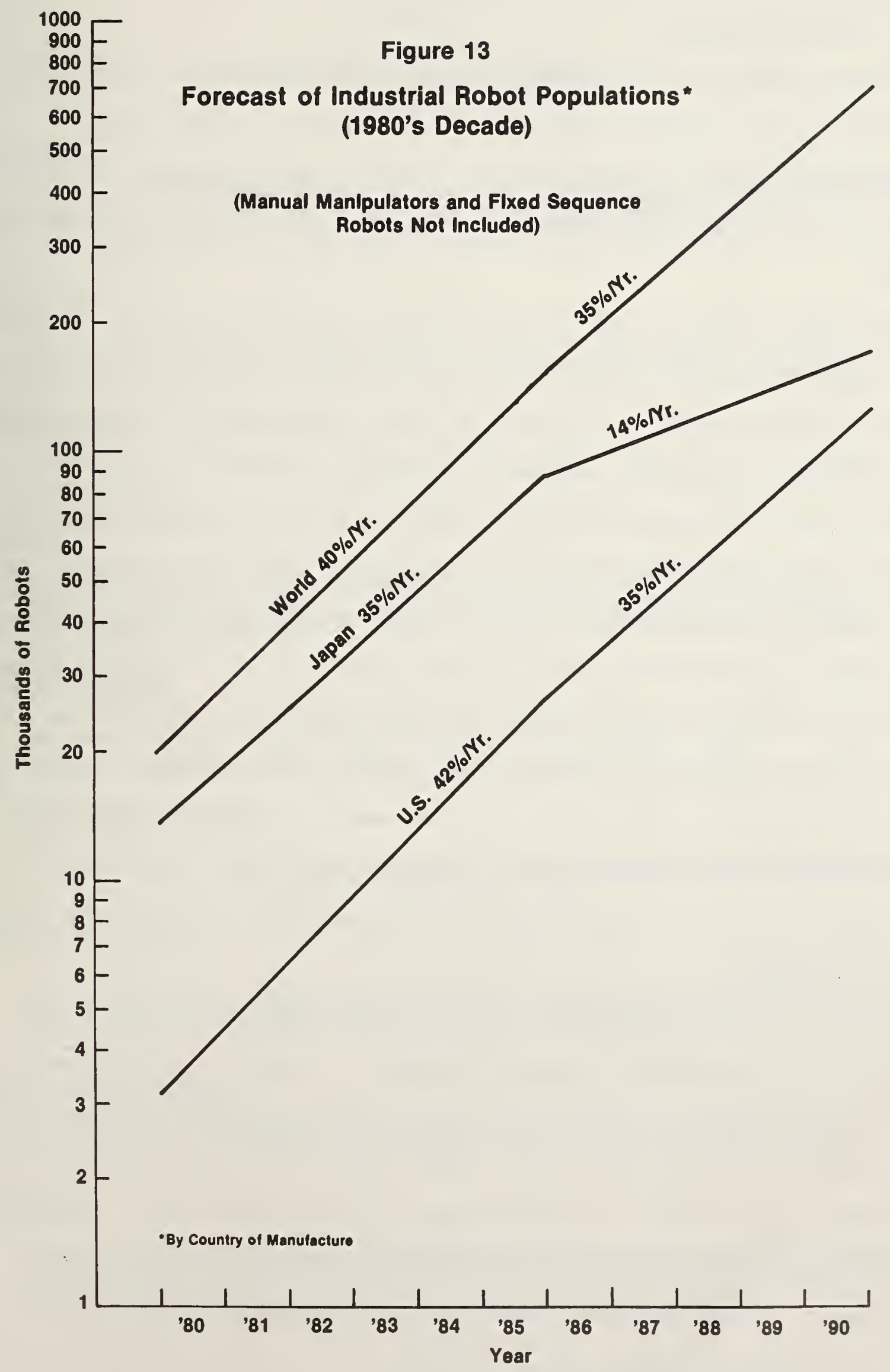


XVIII. Future Directions

Hasegawa (1981, pp. 169-170) makes the forecast of unfolding robot technology given in Figure 14. Based on these technological trends, he states that "... industrial robots will become smarter, smaller, quicker, lighter, stronger, more ingenious, easier to operate, more intelligent and less expensive that they are now."

Engelberger (1980, p. 118) lists in Figure 5 the qualities sought in future robots. He indicates that these qualities will be, for the most part available during the current decade. Of the missing robotic attributes, he considers the two crucial ones to be vision and tactile sensing.

JIRA (The Long-Term Credit Bank of Japan, 1981, p. 59) indicates that the technology for robot miniaturization, modularization, high speed operation, and computer control has advanced to the point where it is now available and will grow in popularity and acceptance in the first half of this decade. Technology for part recognition and position determination is also currently available, but won't receive widespread popularity until the second half of this decade. Technology for color and behavior recognition, automated assembly, and machine tool and casting robotics won't become adequately advanced until later in the first half of the decade and therefore won't achieve widespread popularity until the second half of the $1980^{\prime} \mathrm{s}$.

One of the greatest advantages of robotics and automation occurs in the cases where their use greatly increases equipment utilization. Albus (1981B) indicates that a robot arc welder cannot weld faster than a human, but by keeping its torch on the work about $90 \%$ of the time, versus no more than $30 \%$ of the time for a human, it can turn out 3 times as much work in the same time. If through automation more shifts can be worked, productivity is even further increased. Unfortunately, present day robots cannot set up their own work, so this reduces their productivity advantage. Albus conjectures: 
Figure 14

Forecast of Robot Technology

\section{- Materials}

Lighter and stronger materials for robot structures will be developed. These will include both organic and non-organic substances. As a consequence, the size and weight of robots will decrease.

\section{- Power Sources}

Smal1, high-capacity power sources such as nuclear powered generators or fuel cells will allow robots greater freedom of location and movement.

\section{- Actuators}

Small, high performance actuators will appear. Robot designs will be more stylish.

\section{- Sensors}

Sma11, reliable, high-performance, low-cost artificial eyes, ears, and tactile sensors will be developed and even low-cost robots will have recognition capability.

\section{- Control Systems}

Advances in microcomputer technology will dramatically improve robot control. Control system costs will also be greatly reduced.

\section{- Communications Systems}

Remote control of industrial robots will be enhanced through development in fiber optics, wireless communcations, etc.

\section{- Processing Methods}

New, non-mechanical processing methods such as laser beam cutting, welding and other high-energy processing methods will reduce the processing load on robots and make the design work for them simpler.

\section{- Robot Body Structure}

Utilization of biomechanical concepts will result in superior robot structures.

\section{- Software}

Robot use will become easier through the development of robot languages, self-diagnosing systems and robot application technologies. Sof tware will contribute to reducing the design work needed on robots. 


\section{Figure 14 (cont'd)}

\section{- Integrated Systems}

Techniques for integrating production systems composed of men, machines and robots as well as their peripheral devices will be found. Further, their design processes will be computerized.

Source: Hasegawa, 1981, pp. 169-170. 
Eventually, welding robots will be sufficiently sophisticated to work from plans stored in computer memory and to correct errors which may occur during a job. Welding robots will then be able to work nights and weekends (four shifts per week) completely without human supervision. At that point productivity improvements over present methods of many hundreds of percent become possible. Unfortunately, we are a long way from that today. There are many difficult research and development problems that must be solved first. Unless the level of effort in software development is increased many fold, these improvements will not be realized for many years.

In the metal cutting industry, Albus (pp. 16-18) predicts,

During the 1980 's, robot sensory and control capabilities will improve to the point where robots can find and load unoriented parts, or in some cases, even pick parts out of a bin filled with randomly oriented parts lying on top of each other. This may improve productivity by hundreds of percent because it will make it possible to install robots in many existing plants without major reengineering of production methods....

By 1990 robots may begin to have a significant impact on mechanical assembly. There has been a great deal of research effort spent on robot assembly. Unfortunately, the results have not been spectacular--yet. On the one hand, robots cannot compete with classical so-called "hard automation" in assembly of mass produced parts. General purpose machines like robots are still too slow and too expensive to be economical for mass production assembly tasks. On the other hand, robots cannot yet compete with human assembly workers in small lot assembly. Humans are incredibly adaptable, dexterous, as well as fast, skilled, and relatively cheap compared to robots...

Nevertheless, progress is being made and will continue. Robot capabilities will gradually increase. Sensory systems will become more sophisticated and less expensive. The cost of computer hardware is dropping rapidly and steadily with no sign of bottoming out. Software costs are likely to be the major impediment to robot development of the foreseeable future, but even these are slowly. yielding to the techniques of structured programming and high level languages.

Eventua11y, extremely fast, accurate, dexterous robots will be programmed using design graphics data bases which describe the shape of the parts to be made and the configuration of the assemblies to be constructed. Eventually, robots will be able to respond to a wide variety of sensory cues, to learn by experience 
and to acquire skills by self optimization. Such skills can then be transferred to other robots so that learning can be propagated rapidly throughout the robot labor force.

Sometimes, perhaps around the turn of the century, robot technology will develop to the degree necessary to produce the totally automated factory. In such factories robots will perform most, if not all, of the operations that now require human skills. There will be totally automatic inventory and tool management, automatic machining, assembly, finishing, and inspection systems. Automatic factories will even be able to reproduce themselves. That is, automatic factories will make the components for other automatic factories.

Once this occurs, productivity improvements will propagate from generation to generation. Each generation of machines will produce machines less expensive and more sophisticated than themselves. This will bring about an exponential decline in the cost of robots and automatic factories which may equal the cost/performance record of the computer industry...

Eventually, products produced in automatic factories may cost only slightly more than the raw materials and energy from which they are made.

In summary, what we see emerging are robots with increasing intelligence, sensory capability, and dexterity. Initially, we will see an increasing use of off-line programming of computer-controlled robots, using improved robot command languages. Provision will be made to include the role of sensors, such as vision and touch, in this programming. Later, self-planning will emerge as higher and more general commands are given to the robot. At this point, the marriage of robotics and artificial intelligence will be virtually complete. At the same time as all this is taking place, robotic hands with improved dexterity (so that it will not be necessary to move the entire arm for fine motions), and advanced control systems to support this dexterity, will emerge. Also emerging will be robots with coordinated multiple arms and eventually even legs, supported by even more sophisticated control systems. 
As this evolution progresses, information and intelligence will become the dominant factor in robotics, with the manipulator devices and sensors shrinking in importance to the skeleton that undergirds this dominating "ghost in the machine". 


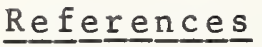

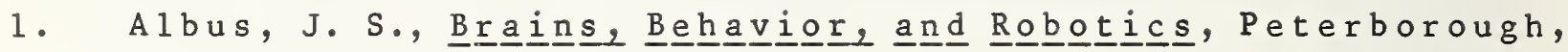
N.H.: BYTE BOOks, $1981 \mathrm{~A}$.

2. Albus, J. S., "Industrial Robots and Productivity Improvement," Summary and Report of an Exploratory Workshop on the Soccial Impact of Robotics, Office of Technology Assessment, Washington, D.C., July 24,1981 B.

3. Barrow, H. G., and Tenenbaum, J. M., "Computational Vision,"

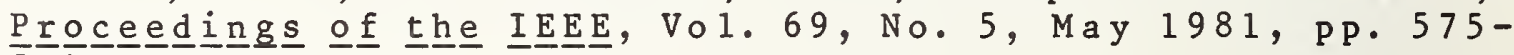
579 .

4. Birk, J. R., and Kelley, R. B., "An Overview of the Basic Research Needed to Advance the State of knowledge in

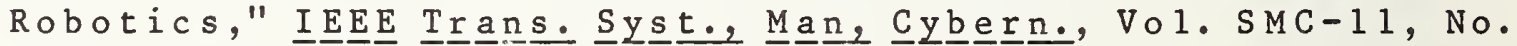
8, Aug. $198 \overline{1}$, P P. $5 \overline{7} 5 \overline{-5} 79$.

5. Congliaro, L., "Robotics Presentation Institutional Investors Conference: May 28, 1981," Ba ach he Robotics Newㅗletter 81-429, New York: Bache Halsey Stuart Shields, Inc., Oct. 28,1981 .

6. Engelberger, J. F., Robots in Practice, New York: American Management, 1980 .

7. Gleason, G. J., and Agin, G. J., "A Modular Vision System for Sensor-Controlled Manipulation and Inspection," Proceed-

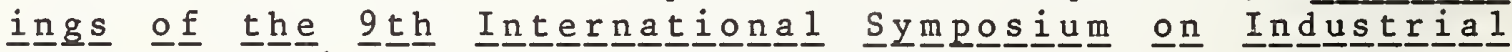
으으은, Washington, D.C., March 1979 .

8. Kelly, F., and Huston, R., "Recent Advances in Robotics Research," SAE Technical Paper 800383 , Feb. 1980.

9. Kinnucan, P., "How Smart Robots are Becoming Smarter," High

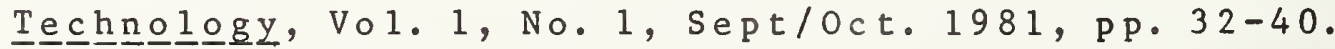

10. Ogawa, E., "Technical Development in Small and Medium-sized

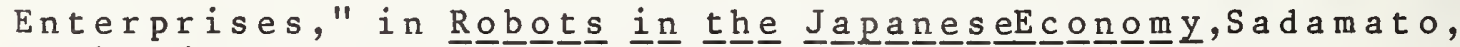

K. (Ed.), Tokyo: Survey Japan, 1981, P . 113-150.

11. Plantier, M. and Bodmer, R., et a 1., "Teleoperation and Automation: A Survey of European Expertise Applicable to Docking and Assembly in Space," ESTEC Contract No. $4402 / 80 / \mathrm{NL} / \mathrm{AK}$ (SC), Geneva: EUROSTAT, S.A., May 1981 .

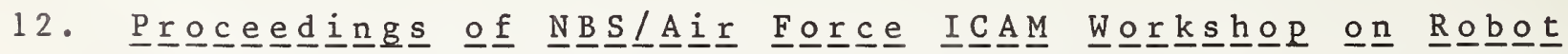

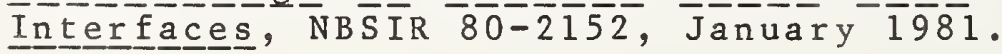

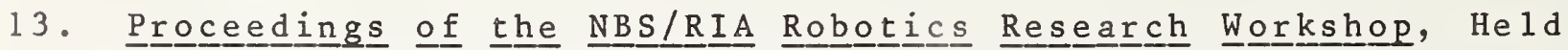
at NBS, Gaithersburg, MD, Nov. 13-15, 1979, NBS SP 602 . 
14. Rheinhold, A. G., and Vanderbrug, G., "Robot Vision for Industry: The Autovision System," Robootics Age, Vol. 2, No. 3, Fal1 1980 , pp. 22-28.

15. "Robots Join the Labor Force," Business Week, June 9, 1980, p . 62-76.

16. Rosen, C. A., "Machine Vision and Robotics: Industrial Requirements," TN 174 , SRI Internationa 1, Menlo Park, CA, November 1978 .

17. Rosso1, L., "Vision and Adaptive Robots in General Motors,"

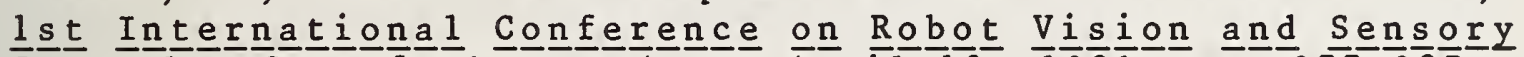
Controls, Strat ford-upon-Avon, Apri1 $13, \overline{1} 981, \mathrm{pp} \cdot 27 \overline{7}-287$.

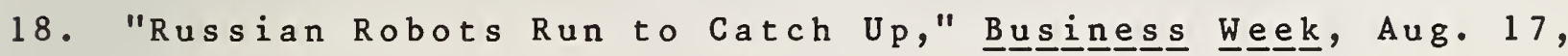
1981, p. 120 .

19. Saveriano, J. W., "Industria 1 Robots Today and Tomorrow,"

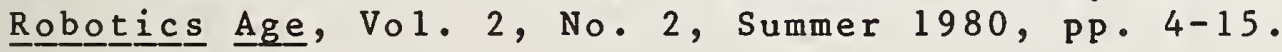

20. Scheinman, V., "The Autovision system Computerized Vision for Factory Automation," Presented at the 11 th International Symposium on Industrial Robots, Tokyo, October 1981 .

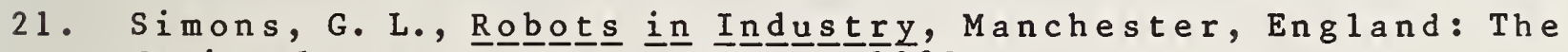
National Computer Center Ltd., 1980 .

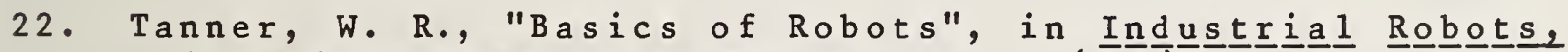

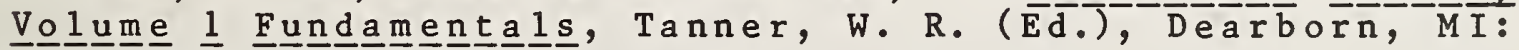
$\overline{\mathrm{SM}} \frac{\mathrm{E}}{19}, \overline{79}, \mathrm{PP} \cdot \overline{3}-12$.

23. Toepperwein, et a 1., "ICAM Robotics Application Guide (RAG)," ARWAL-TR-80-4042, Vo1. II, Air Force Wright Aero. Labs, Wright Patterson AFB, Ohio, April 1980 .

24. Teschler, L., "How Good is Soviet Robot Technology," Machine Design, Oct. 8, 1981 , pp. 43-48.

25. "The Push for Dominance in Robotics Gains Momentum," Busiㅡㄹㅗs Week, December 14, 1981, pp. 108-109.

26. Umentani, Y., "Research and Development of IR's in Japan,"

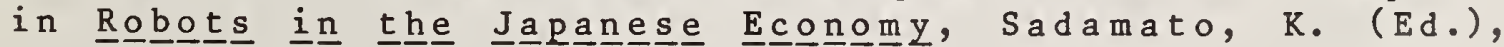
Tokyo: Survey Japan, 1981, pp. $79-104$.

27. Yonemoto, K., "The Art of Industrial Robots in Japan," in

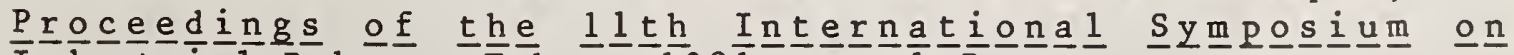

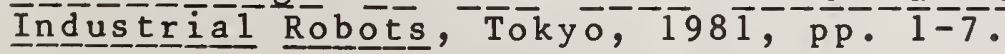


BIBLIOGRAPHIC DATA

SHEET (See instructions) 1. PUBLICATION OR
REPORT NO.

NBSIR $82-2479$
2. Performing Organ. Report No, 3. Publication Date

March 1982

4. TITLE AND SUBTITLE

ON OVERVIEW OF ARTIFICIAL INTELLIGENCE AND ROBOTICS

Volume II -Robotics

5. AUTHOR(S)

Dr. William B. Gevarter

6. PERFORMING ORGANIZATION (If joint or other than NBS, see instructions)

7. Contract/Grant No.

NATIONAL BUREAU OF STANDARDS

DEPARTMENT OF COMMERCE

WASHINGTON, D.C. 20234

9. SFONSORING ORGANIZATION NAIE ANO COMPLETE ADDRESS (STFEl, CIIY, StOTE, ZIP)

National Aeronautics and Space Administration

Headquarters

Washington, D.C. 20546

10. SUPPLEMENTARY NOTES

Document describes a computer program; SF-185, FIPS Software Summary, is attached.

11. ABSTRACT (A 200-word or less foctual summary of most significant information. If document includes a significant

bibliography or literature survey. mention it here)

This report provides an overview of the rapidly changing field of robotics. It is intended to be read by the technically oriented layman, such as engineering managers, government funding offices, and others who desire an overall perspective of the field but are unable to obtain it from the highly technical and unintegrated literature in the field, or from the more flamboyant but non-technical feature articles in the popular press.

The report incorporates definitions of the various types of robots, a summary of the basic concepts utilized in each of the many technical areas, review of the state-ofthe-art and statistics of robot manufacture and usage. Particular attention is paid to the status of robot development, the organizations involved, their activities, and their funding. A 5-10 year forecast of the emerging technology is also included.

The majority of the material in this report is drawn from the activities in the U.S. and Japan, the principle players in the world of robotics.

12. KEY WORDS (Six to twelve entries; alphabetical order; capitalize only proper names; and separate key words by semicolons) Applications; Forecast; Japan; Overview: Research and Development; Robot;

State-of-the-art.

Order From Superintendent of Documents, U.S. Government Printing Office, Washington, D.C. 20402.

X] Order From National Technical Information Service (NTIS), Springfield, VA. 22161

14. NO. OF

PRINTED PAGES

15. Price 

